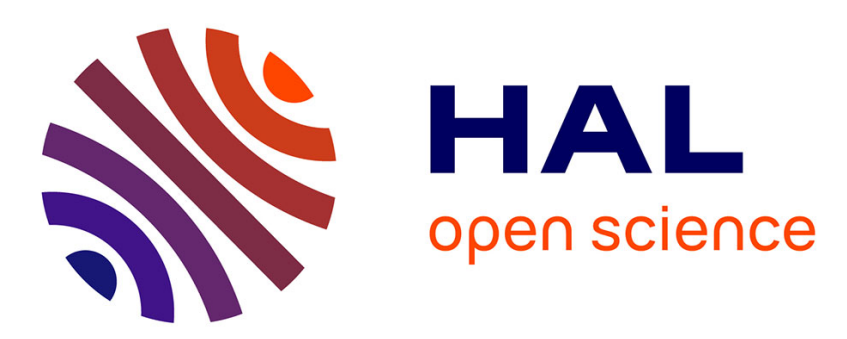

\title{
Skeletal muscle of females and males with constitutional thinness: a low intramuscular lipid content and oxidative profile
}

Mélina Bailly, Natacha Germain, Léonard Féasson, Frédéric Costes, Bruno Estour, Christophe Hourdé, Angèle N. Merlet, Thierry Thomas, Jörg Hager, Bruno Pereira, et al.

\section{To cite this version:}

Mélina Bailly, Natacha Germain, Léonard Féasson, Frédéric Costes, Bruno Estour, et al.. Skeletal muscle of females and males with constitutional thinness: a low intramuscular lipid content and oxidative profile. Applied Physiology, Nutrition, and Metabolism, 2020, 45 (11), pp.1287-1298. 10.1139/apnm2020-0068 . hal-03011948

\author{
HAL Id: hal-03011948 \\ https://hal.uca.fr/hal-03011948
}

Submitted on 18 Nov 2020

HAL is a multi-disciplinary open access archive for the deposit and dissemination of scientific research documents, whether they are published or not. The documents may come from teaching and research institutions in France or abroad, or from public or private research centers.
L'archive ouverte pluridisciplinaire HAL, est destinée au dépôt et à la diffusion de documents scientifiques de niveau recherche, publiés ou non, émanant des établissements d'enseignement et de recherche français ou étrangers, des laboratoires publics ou privés.

$$
\text { Copyright }
$$




\title{
Skeletal muscle of females and males with constitutional thinness:
}

\author{
a low intramuscular lipid content and oxidative profile
}

\author{
Mélina BAILLY ${ }^{\mathrm{a}, \mathrm{b}}$, Natacha GERMAIN ${ }^{\mathrm{b}, \mathrm{c}}$, Léonard FÉASSON ${ }^{\mathrm{d}}$, Frédéric COSTES ${ }^{\mathrm{e}}$, Bruno \\ ESTOUR $^{\text {b,c }}$, Christophe HOURDÉf ${ }^{\mathrm{f}}$ Angèle N MERLET ${ }^{\mathrm{d}}$, Thierry THOMAS $^{\mathrm{g}, \mathrm{h}}$, Jorg HAGER ${ }^{\mathrm{i}}$, \\ Bruno PEREIRA ${ }^{j}$, David THIVEL ${ }^{a}$, Daniel COURTEIX ${ }^{a}$, Bogdan GALUSCA $^{\text {b,c }}$, Julien \\ VERNEY ${ }^{a}$
}

a Université Clermont Auvergne, CRNH, AME2P, F-63000 Clermont-Ferrand, France, melina.bailly@uca.fr, julien.verney@uca.fr, daniel.courteix@uca.fr, david.thivel@uca.fr; b Eating Disorders, Addictions and Extreme Bodyweight Research Group (TAPE) EA 7423, Jean Monnet University, Saint-Étienne, France, natacha.germain@chu-st-etienne.fr, bogdan.galusca@chu-stetienne.fr, bruno.estour@chu-st-etienne.fr; ${ }^{\mathrm{c}}$ Division of Endocrinology, Diabetes, Metabolism and Eating Disorders, CHU Saint-Étienne, France; ${ }^{\mathrm{d}}$ Inter-university Laboratory of Human Movement Biology (LIBM) EA 7424, Jean Monnet University, Saint-Étienne, France, leonard.feasson@ univ-stetienne.fr, angelemerlet@gmail.com; ${ }^{e}$ Department of Sport Medicine and Functional Explorations, CHU Clermont-Ferrand, France, fcostes@chu-clermontferrand.fr; ${ }^{f}$ Inter-university Laboratory of Human Movement Biology (LIBM) EA 7424, Savoie Mont Blanc University, Chambéry, France, christophe.hourde@univ-smb.fr; g Department of Rheumatology, Hôpital Nord, CHU Saint-Etienne, France, thierry.thomas@chu-st-etienne.fr; h INSERM U1059, University of Lyon-Jean Monnet University, Saint-Étienne, France; i Metabolic Health, Nestlé Research, EPFL Innovation Park, Lausanne, Switzerland, jorg.hager@rd.nestle.com; ${ }^{\mathrm{j}}$ Biostatistics Unit, Délégation à la Recherche Clinique et à l'Innovation (DRCI), Clermont-Ferrand, France, bpereira@ chu-clermontferrand.fr

Corresponding Author: Mélina BAILLY, Université Clermont Auvergne, CRNH, AME2P, F-63000

Clermont-Ferrand, France, melina.bailly@uca.fr

Novelty: •Low intramuscular triglycerides and glycogen content in skeletal muscle of constitutionally thin individuals; • Low oxidative capacity, low capillary supply, and fiber hypotrophy in skeletal muscle of constitutionally thin participants; •Increase in intramuscular triglycerides in constitutional thinness in response to overfeeding

Keywords: Constitutional thinness; Skeletal muscle; Intramuscular triglycerides; Oxidative capacity; Muscle glycogen; Capillary supply 


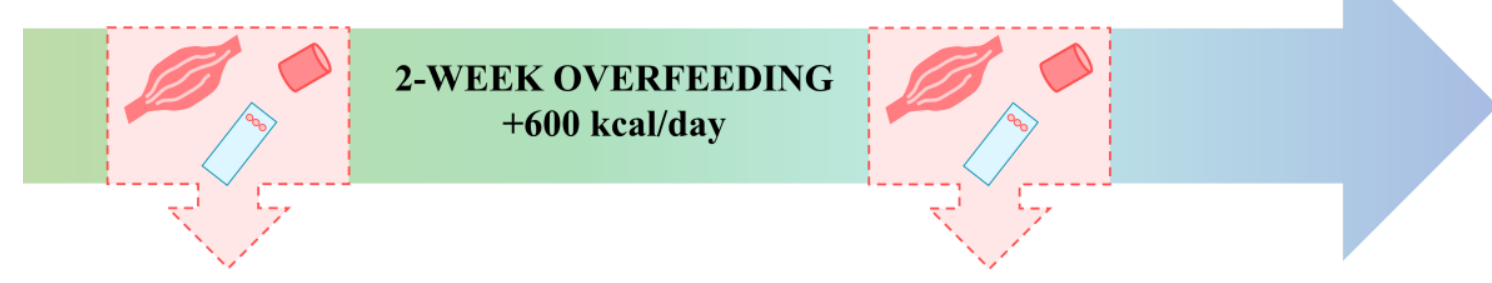

\section{PRE-OVERFEEDING}

\section{Constitutionally thin subjects 15 females, 15 males}

- Intramuscular triglycerides:

- Glycogen content:

- Cross-sectional area of fibers:

- Capillary supply:

- Citrate synthase activity:

- Cytochrome c Oxidase:

- Type IIX fibers:

LOW OXIDATIVE PROFILE

\section{POST-OVERFEEDING}

\section{Constitutionally thin subjects}

- Intramuscular triglycerides:

- Glycogen content:

- Capillary supply:

- Citrate synthase activity: $\Rightarrow$

- Cytochrome c Oxidase:

vs.

Normal-weight control subjects 16 females, 15 males

Graphical abstract 


\section{Abstract}

Constitutional thinness (CT) is a non-pathological state of underweight. The present study aimed to explore skeletal muscle energy storage in individuals with constitutional thinness and to further characterize muscle phenotype at baseline and in response to overfeeding. Thirty subjects with CT (15 females, 15 males) and 31 normal-weight control subjects (16 females, 15 males) participated in the study. Histological and enzymological analyses were performed on muscle biopsies before and after overfeeding. In skeletal muscle of CT participants compared to controls, it was observed a lower content in intramuscular triglycerides for type I $(\mathrm{p}<0.01,-17 \%)$ and type IIA $(\mathrm{p}<0.05,-14 \%)$ muscle fibers, a lower glycogen content for type I fibers $(\mathrm{p}<0.01,-6 \%)$ and type IIA fibers $(\mathrm{p}<0.05,-5 \%)$, a specific fiber type distribution, a marked muscle hypotrophy $(\mathrm{p}<0.001,-20 \%)$, a low capillary-to-fiber ratio ( $<<0.001$, $-19 \%)$, and a low citrate synthase activity $(\mathrm{p}<0.05,-18 \%)$. In response to overfeeding, CT participants increased their intramuscular triglycerides content in type $\mathrm{I}(\mathrm{p}<0.01,+10 \%)$ and type IIA $(\mathrm{p}<0.01,+9 \%)$ muscle fibers. CT individuals seem to present an unusual muscle phenotype and different adaptations to overfeeding compared to normal-weight participants, suggesting a specific energy metabolism and muscle adaptations. NCT02004821 


\section{Introduction}

While the potential existence of thinness due to a constitutional origin was first suggested in 1933 (Grafe 1933), the scientific literature remains quite limited more than 85 years later with only about 40 heterogeneous studies investigating it. Given this lack of medical and scientific interest, this constitutional thinness (CT) is poorly recognized, diagnosed, and documented. Despite an increasing number of clinical consultations, it remains difficult to provide appropriate medical support and to help CT individuals overcome their weight gain resistance. People with CT present a low body mass index (BMI) $\left(<18.5 \mathrm{~kg} \cdot \mathrm{m}^{2}\right)$, no eating disorder-related traits as anorexia nervosa (AN) or any other eating disorders, and no over-exercising or associated diseases that could induce underweight (Scalfi et al. 1992; Bosy-Westphal et al. 2004; Tagami et al. 2004; Bossu et al. 2007; Marra et al. 2009, 2019; Hasegawa et al. 2011; Estour et al. 2014, 2017; Germain et al. 2014, 2016; Galusca et al. 2015, 2018; Riveros-McKay et al. 2019; Margaritelis et al. 2019; Ling et al. 2020). Despite a potentially more fractionated energy intake with smaller portioned-meals and more snacking (Germain et al. 2014; Ling et al. 2020), individuals with CT have a similar total daily energy intake compared to normal-weight controls (Germain et al. 2007, 2014; Estour et al. 2014). They also have similar proportions in macronutrient intake (Bossu et al. 2007; Galusca et al. 2018) and do not seem to present any signs of impairments in their gastrointestinal fat absorption, such as steatorrhea (Ling et al. 2019). Individuals with CT nevertheless present an unusual phenotype of impaired bone quality with a low bone mineral density (Galusca et al. 2008, 2018; Fernández-García et al. 2009; Hasegawa et al. 2011), a low bone mass, and a diminished breaking strength, despite an apparently normal bone turnover (Galusca et al. 2008). These data obtained in young adults ( $<36$ years) suggest a potential increased risk of osteoporosis with aging in CT population, even if it remains to be shown. Given the well-known strong connection between bone and muscle tissues, usually called the "functional muscle-bone unit" (Fricke and Schoenau 2007), skeletal muscle alterations might also be expected in CT. In addition, two studies found a significantly higher resting metabolic rate (RMR) to fat-free mass (FFM) ratio in both CT females 
(Bossu et al. 2007) and CT males (Marra et al. 2019) compared to normal-weight controls, underlying a potential increased muscle metabolism in CT individuals of each gender. However, RNA profiling in skeletal muscle reported that fat storage-inducing transmembrane 1 and 2 (respectively FITM1 and FITM2) genes involved in triglycerides metabolism were downregulated in CT females, on top of an unusual and untypical skeletal muscle phenotype (Galusca et al. 2018). In light of these findings, it seems of major interest to investigate the storage and use of muscle energy substrates to better understand and help CT individuals. To the best of our knowledge, no studies have been conducted to date on muscle energy storage (i.e. intramuscular triglycerides (IMTG) and glycogen content (Essén et al. 1975)) and its metabolic implications in CT. Clinically, the main issue for medical practitioners remains to provide appropriate strategies to help CT patients gain weight, as it has been discussed for a long time (Wissmer 1953; Aubertin 1953; Passmore et al. 1955; Genest et al. 1955; Apfelbaum and Sachet 1982). More recently, a 4 -week fat overfeeding of 630 extra kcal/day failed to increase bodyweight in CT women compared to controls but interestingly increased RMR-to-FFM ratio in CT participants contrary to controls (Germain et al. 2014). We, therefore, hypothesized that specific adaptations in muscle metabolism of CT individuals could partly explain their weight gain resistance. The aim of the present study was first to investigate muscle energy storage and skeletal muscle phenotype in a large subset of both females and males with CT, compared to normal-weight control volunteers at baseline. The second objective was to explore muscle storage and muscle phenotype in response to overfeeding containing proteins, carbohydrates, and fats, in CT participants compared to normal-weight controls.

\section{Materials and methods}

The present clinical investigation was a large-scale study developed in partnership with the Nestlé Institute of Health Sciences (NIHS). This investigation was conducted in accordance with the Helsinki Declaration, last updated in 2013 and was registered in clinical-trial.gov as NCT02004821. The local 
research and ethics committee of Saint-Étienne - France approved the study and all subjects gave written informed consent prior to inclusion in the study.

\section{Subjects}

Sixty-one subjects participated in the study: 30 CT subjects (15 females and 15 males) and 31 normalweight controls (16 females and 15 males). CT females were recruited with a BMI between 13 and 17.5 kg.m-2, CT males with a BMI between 13 and 18.5 kg.m-2, and control females and males with a BMI between 20 and $25 \mathrm{~kg} . \mathrm{m}^{-2}$. The inclusion criteria for all participants were: age between 18 and 35 years (mean age of $23.1 \pm 2.9$ years for controls and $25.5 \pm 4.5$ years for CT participants), stable weight for at least 3 months, no over-exercising (according to the MOSPA questionnaire (Iqbal et al. 2006)), agreement to a potential weight gain of $2 \mathrm{~kg}(<10 \%$ of bodyweight $)$, no chronic or congenital diseases, and no medications. Normal-weight control subjects were recruited by advertising and participants with CT were recruited among outpatients consulting for bodyweight gain desire at the division of Endocrinology, Diabetes, Metabolism and Eating Disorders of the CHU Saint-Étienne, France. The specific inclusion criteria of CT participants were: no AN traits or other eating disorders confirmed by psychiatric evaluation and validated psychological questionnaires (Dutch eating behavior questionnaire (DEBQ) (van Strien et al. 1986), eating disorder inventory (EDI) (Garner et al. 1983), eating disorder examination questionnaire (EDE) (Cooper and Fairburn 1987), and body shape questionnaire (BSQ) (Cooper et al. 1987)), stable bodyweight for at least 3 months and also throughout the post-pubertal period, no amenorrhea, normal insulin-like growth factor 1 (IGF-1), estradiol, free triiodothyronine (FT3), cortisol, and non-blunted leptin. The exclusion criteria for all participants were: eating disorders (DSM-IV) or other psychiatric conditions, intensive physical activity (more than 3 sessions of physical activity per week), vegetarians or lactose-intolerant subjects, significant alcohol or tobacco consumption (> 10 glasses of wine per week or $>10$ cigarettes per day), severe progressive disorder, and surgical history or treatment deemed incompatible with the study. For further details, see the complete design of the protocol (Ling et al. 2016). 


\section{Overfeeding protocol}

All participants (CT and control groups) had to complete an extra consumption of $600 \mathrm{kcal}$ per day for 2 weeks, by adding one bottle of Renutryl ${ }^{\circledR}$ Booster $(300 \mathrm{~mL})$ to their usual diet, every evening. One bottle of Renutry $1^{\circledR}$ Booster contained $30 \mathrm{~g}$ of proteins, $72 \mathrm{~g}$ of carbohydrates, $21 \mathrm{~g}$ of fats, minerals, and oligo-elements. Twenty percent of the energy contained in one bottle came from proteins, $48.5 \%$ from carbohydrates and 31.5\% from fats (Supplementary Table S1). To the best of our knowledge, only one publication investigated the effects of an overfeeding in CT individuals (Germain et al. 2014). This 4week fat overfeeding of 630 extra kcal per day showed an increase in bodyweight of CT participants which did not persist after the first 2 weeks (Germain et al. 2014; Ling et al. 2016). It, therefore, appeared that an overfeeding of fat exclusively might not be the best strategy to increase bodyweight of CT participants, and we hypothesized that a more balanced nutritional composition could be more relevant. In addition, these previous observations suggested that a 2-week overfeeding could be a better duration than 4 weeks in order to observe changes in CT. Thus, the duration of overfeeding was reduced to 2 weeks in the present study while maintaining the same range of extra calories $(630 \mathrm{kcal}$ per day in our previous study (Germain et al. 2014), and $600 \mathrm{kcal}$ per day in the present one). This shorter duration was also designed to maximize our confidence in compliance and recruitment of participants. Except for the extra consumption of one bottle of Renutryl ${ }^{\circledR}$ Booster per day after dinner in free-living conditions, participants were asked not to modify their regular lifestyle (baseline diet and physical activities) during the whole study. Instead of the previously used real food (Germain et al. 2014), the present overfeeding consisted of a multi-nutrient liquid in order to facilitate the ingestion of extra calories. Throughout the protocol, participants were regularly in contact with the investigators to check compliance and avoid compensatory behaviors. Compliance of overfeeding was defined as an increase in food intake of at least $450 \mathrm{kcal} / \mathrm{day}$, a positive change in urine urea, and no increase in physical activity level (PAL) (Ling et al. 2020). Only participants who complied with overfeeding were included in post-overfeeding statistical analyses, i.e. 22 normal-weight and 24 CT participants. 


\section{Anthropometry, body composition, and physical activity level}

Bodyweight was measured with a digital scale (ProDoc, PD200M, Detecto, Webb City, USA) to the nearest $0.1 \mathrm{~kg}$ and body height was recorded with a standard wall-mounted stadiometer to the nearest $0.1 \mathrm{~cm}$. Fat mass (FM) and lean mass measurements were assessed by Dual-energy X-ray Absorptiometry (LUNAR, DPX-L). PAL was measured in free-living conditions for 5 days with an accelerometer (ActiHeart ${ }^{\circledR}$, CamNtech, Cambridge, UK).

\section{Muscle biopsies collection}

A biopsy of 100 to $150 \mathrm{mg}$ of the vastus lateralis muscle was performed with an incision by a specializedsurgeon at one-third of the distance from the upper margin of patella to the anterior superior iliac spine, using Weil-Blakesley forceps under local anesthesia. The biopsy was performed on the right leg just before overfeeding and on the left leg at the end of overfeeding. Samples were divided to perform histological and enzymatic analyses. A piece of the sample containing well-identified fascicles was oriented under a stereo microscope, included in an embedding medium (Cryomount, Histolab, Göteborg, Sweden), frozen in isopentane cooled to its freezing point in liquid nitrogen and stored at $-80^{\circ} \mathrm{C}$. Serial $10 \mu \mathrm{m}$ thick transverse sections were cut at $-18^{\circ} \mathrm{C}$ using a cryostat (CM1950, Leica Biosystems, Wetzlar, Germany), mounted on glass slides, air-dried at room temperature, and stored at $-20^{\circ} \mathrm{C}$. Before staining, frozen slides were air-dried at room temperature for 45 minutes.

\section{Histological staining (Figure 1)}

\section{Muscle fiber type and muscle capillarization}

Slides were fixed in acetone for 15 minutes, washed in a phosphate-buffered saline solution (PBS) for $3 \times 5$ minutes and then blocked in a PBS solution containing $10 \%$ of goat serum (GS) and $10 \%$ of bovine serum albumin (BSA) for 20 minutes. CD31 (Dako, M0823, Agilent Technologies, Santa Clara, USA) 
primary antibody directed against platelet endothelial cell adhesion molecule (PECAM-1) was used to identify muscle capillaries. The antibody was diluted (1/40) in PBS-10\% GS-10\%BSA and applied for 1 hour. After a PBS wash ( $3 \times 5$ minutes), sections were blocked again with a PBS-10\%GS-10\%BSA solution and then incubated with an appropriate conjugated secondary antibody (1/300, Alexa Fluor A21123, ThermoFisher Scientific, Waltham, USA) for 1 hour. After another washing $(4 \times 5$ minutes in PBS) and blocking (30 minutes in PBS-10\%GS-10\%BSA) baths, sections were incubated in a cocktail of primary antibodies (DSHB, Iowa City, USA) diluted (1/100) in PBS-10\%GS-10\%BSA: BF-35, BAF8 and 2E8 for 1 hour. BA-F8 antibody specifically reacts with type I fibers while BF-35 strongly reacts with type IIA fibers, slightly with type I fibers and not at all with type IIX fibers. 2E8 antibody reacts with laminin. After the last washing ( $4 \times 5$ minutes in PBS) and blocking (30 minutes in PBS-10\%GS$10 \%$ BSA), sections were incubated with a cocktail of appropriate conjugated secondary antibodies diluted (1/300, ThermoFisher Scientific, Waltham, USA) in PBS-10\%GS-10\%BSA during 1 hour. After 3 consecutive 5-min washes in PBS, slides were mounted with a mounting medium ProLong ${ }^{\mathrm{TM}}$ Gold antifade (P36934, ThermoFisher Scientific, Waltham, USA).

\section{Oil Red O staining}

Oil red O (ORO) staining was used to identify IMTG. ORO stock solution was prepared by adding 0.5 $\mathrm{g}$ of ORO (O0625 Sigma-Aldrich, Saint-Louis, USA) for $100 \mathrm{~mL}$ of $60 \%$ triethyl phosphate (538728, Sigma-Aldrich, Saint-Louis, USA). Before the staining, a 36\% triethyl phosphate working solution containing $12 \mathrm{~mL}$ of ORO stock solution for $8 \mathrm{~mL}$ of distilled water was prepared and filtered with Whatman Grade 42 filter paper to remove crystallized ORO. Serial transverse sections were fixed in a 3.7\% formaldehyde (F1635, Sigma-Aldrich, Saint-Louis, USA) solution for 1 hour, rinsed in distilled water and incubated in the ORO working solution for 30 minutes. Slides were then rinsed in distilled water, subsequently rinsed with running tap water for 10 minutes and mounted with Aquatex. 


\section{Periodic Acid Schiff staining}

Periodic acid Schiff (PAS) staining was used to identify muscle glycogen. Serial transverse sections were fixed in Carnoy's solution (60\% ethanol, 30\% chloroform, $10 \%$ glacial acetic acid) for 10 minutes, rinsed in distilled water, treated with $1 \%$ periodic acid for 5 minutes, rinsed in distilled water, incubated in Schiff's reagent (477601, Carlo Erba, Cornaredo, Italy) for 15 minutes at room temperature, and rinsed again. Slides were then dehydrated in alcohol baths $\left(95^{\circ}, 100^{\circ}, 100^{\circ}\right)$, treated with xylene and mounted with Eukitt.

\section{Cytochrome C Oxidase activity evaluation}

Serial transverse sections were incubated for 2 hours at $37^{\circ} \mathrm{C}$ in a solution of $3,3^{\prime}$-diaminobenzidine (DAB) (D5637, Sigma-Aldrich, Saint-Louis, USA) (previously prepared in a phosphate buffer), cytochrome C (C2506, Sigma-Aldrich, Saint-Louis, USA) saccharose, catalase (C100, Sigma-Aldrich, Saint-Louis, USA), rinsed in distilled water, dehydrated in alcohol baths $\left(95^{\circ}, 100^{\circ}, 100^{\circ}\right)$, treated with xylene and mounted with Eukitt.

\section{Image analyses}

Image acquisition was performed with a slide scanner (Axio Scann.Z1, Carl Zeiss, Munich, Germany) and image analyses were achieved with ImageJ software (NIH, Bethesda, USA). Concerning the immunohistochemical technique, different pictures of the same region obtained with different appropriate filters allowed identifying the different types of fibers on a merged picture (Figure 1). Type I, IIA, and IIX fibers were identified and counted to determine fiber type composition. The few coexpressing fibers were classified into a main type (I, IIA or IIX), depending on the fiber type they were the most similar to. This choice was based on under-representation of co-expressing fibers in untrained young adults (Staron et al. 2000) and aimed to perform a fast and large-scale fiber typing (an average of 1421 fibers per biopsy were individually analyzed). The measurement of fiber cross-sectional areas 
(CSA) was performed on 150 fibers of each fiber type. The muscle fibers analyzed were randomly selected in different regions of the muscle section. For type IIX fibers, due to their low number, up to 150 fibers were measured when possible. An overall mean muscle fiber CSA was also calculated as the sum of the products between percentages and mean areas of each type of fibers. The percentage of area occupied by each fiber type was calculated as the product between the proportion and the mean area of each fiber type divided by the overall mean CSA. Muscle capillarization was examined with global indexes (capillary density (CD), capillary to fiber $(\mathrm{C} / \mathrm{F})$ ratio) and local indexes (capillary contact $(\mathrm{CC})$, $\mathrm{CC}$ with sharing factor (SF), capillary to fiber-perimeter exchange (CFPE), capillary contact per fiber area (CAFA)) (Harris 2005). For locales indexes, 40 fibers of each fiber type (or slightly less in case of poor muscle tissue quality) were assessed, randomly chosen. Concerning IMTG, glycogen, and cytochrome $\mathrm{C}$ oxidase (COx) histological analyses, measurements of optical densities were performed by converting images to grayscale before quantifying the mean grey intensity of each muscle fiber. Due to the low prevalence of type IIX fibers, these parameters were only measured in type I and type IIA fibers (50 fibers of each fiber type, randomly chosen). Results were expressed in arbitrary units (AU). An overall index representing each substrates load in the whole muscle section was calculated as the product of optical densities and percentages of area occupied by each fiber type. Since the optical density value of a fiber is the average grey density value of each pixel of the fiber, the measurement does not depend on the fiber size. 


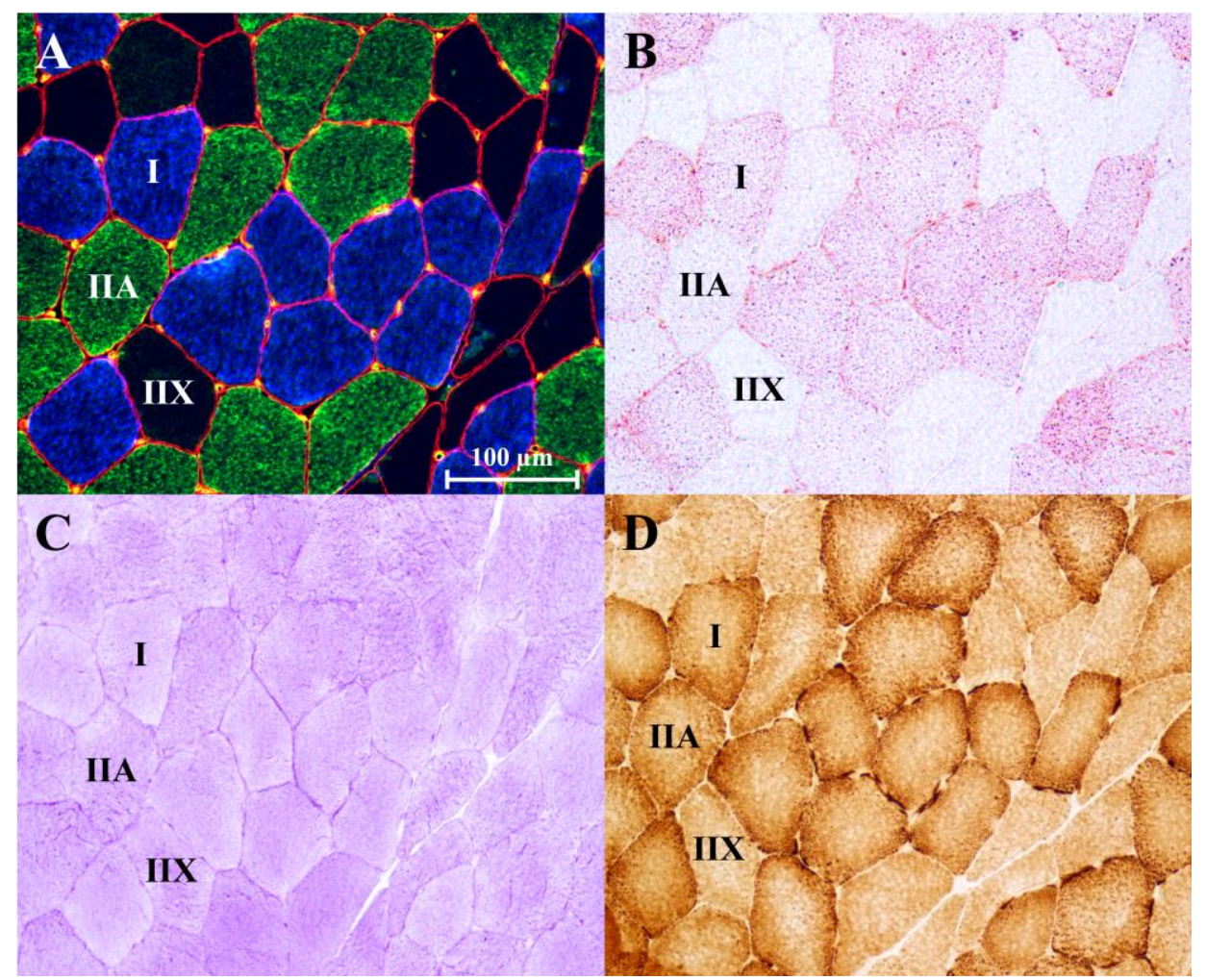

Immunohistochemical serial cross-section staining of muscle fiber type (A), intramuscular triglycerides (IMTG) (B), glycogen content $(\mathrm{C})$, and cytochrome $\mathrm{C}$ oxidase (COx) activity (D). On image A, type I fibers are blue, type IIA fibers are green, type IIX fibers are black (unstained) and laminin is red. Thanks to cross-sectioning, it was possible to identify the corresponding muscle fibers between the fiber type staining (A) and the other stainings (B, C, D).

Figure 1: Staining of skeletal muscle fibers

\section{Enzyme activities evaluations}

The enzyme activity of enolase (ENO), $\beta$-hydroxyacyl-CoA dehydrogenase ( $\beta$-HAD), citrate synthase (CS), second (CII) and fourth (CIV) respiratory chain complexes, lactate dehydrogenase (LDH), myokinase (MK) and creatine kinase (CK) were measured just before and at the end of the overfeeding protocol. Muscle samples underwent a total protein extraction in mannitol buffer with mixing $(3 \times 15$ seconds) and centrifugation (20 minutes $-650 \mathrm{G}$ ), repeated two times to optimize the extraction. Mannitol buffer was composed of D-Mannitol $225 \mathrm{mM}$, Tris-HCl $7.7 \mathrm{mM}$, ethylenediaminetetraacetic acid (EDTA) $0.1 \mathrm{mM}$ and saccharose $75 \mathrm{mM}$. Protein concentrations were measured for each sample 
using a protein assay kit $\left(10752735\right.$, Thermo Scientific ${ }^{\mathrm{TM}}$ Pierce ${ }^{\mathrm{TM}} \mathrm{BCA}^{\mathrm{TM}}$, ThermoFisher Scientific, Waltham, USA) and readjusted to $1 \mu \mathrm{g} . \mu \mathrm{l}-1$. Measurements of the maximal slope of enzyme reactions (i.e. the maximal variation of optical density per minute) were performed by spectrophotometry with a microplate reader (CLARIOstar®, BMG LABTECH, Ortenberg, Germany) at $37^{\circ} \mathrm{C}$, with appropriate reaction mediums and substrates in excess. Enzyme activities were expressed in international unit (IU) per mg protein ( $\mu$ mol.min-1.mg-1).

The evaluation of clinical characteristics and myocellular assessments were performed pre and postoverfeeding.

\section{Statistics}

The statistical analyses were carried out using Stata statistical software (version 13, StataCorp, College Station, USA) and the graphs were obtained using GraphPad Prism 5.0 software. The tests were twosided, with a type-I error set at 5\%. Hedges' g effect size (ES) was estimated and presented with 95\% confidence interval. Continuous data were expressed as mean \pm standard deviation (SD). The assumption of normality was studied using the Shapiro-Wilk test. The following effects - Group, Sex and Group $\times$ Sex interaction at baseline - were estimated using multivariable analyses (i.e. multiple linear regression) taking into account possible confounders such as age and PAL. The normality of residuals was studied as aforementioned. When appropriate, a logarithmic transformation was used to achieve the normality of dependent variables. Multivariable analyses adjusted for age and PAL were also performed to evaluate Group effect by Gender sub-groups, before overfeeding. The relationships between continuous parameters at baseline were assessed using correlation coefficients (Pearson or Spearman, in accordance with statistical distribution), applying a Sidak's type I error correction for multiple comparisons. These correlations' results were illustrated with a color-coded heatmap. Finally, to examine the effect of the 2-week overfeeding intervention, random-effects models (i.e. linear mixed models) were performed to measure group, time-point evaluation, and their interaction effects, taking 
into account between and within-participant variability (subject as random-effect) and adjusting analyses for age, PAL and Sex. As discussed for non-repeated data analyses, the normality of residuals was studied and when appropriate, a logarithmic transformation was used to achieve normality.

\section{Results}

\section{Baseline analysis}

\section{Anthropometry and body composition}

As it was intended, weight and BMI of the CT group was largely lower compared to controls $(\mathrm{p}<0.001$, respectively $-30 \%$ and $-26 \%$ ) (Table 1), and FM percentage was also found lower $(\mathrm{p}<0.001)$. Total FM, total lean mass and right leg lean mass (site of the pre-overfeeding muscle biopsy) were all found lower in CT group compared to controls ( $\mathrm{p}<0.001$; respectively $-48 \%,-22 \%$ and $-29 \%)$. PAL was lower in CT group compared to controls ( $\mathrm{p}=0.006$, ES: $0.37[0.11 ; 0.63])$. This result was also observed for CT males $(p=0.008$, ES: $0.52[0.14 ; 0.89])$, but was not significant for CT females $(p=0.69$, ES: $0.07[-0.30 ; 0.45])$ (Table 1).

\section{Fiber type distribution and CSA}

Percentages of type I and type IIA fibers were found similar between groups but CT participants had higher percentages of type IIX muscle fibers (Table 1). Proportions of fiber types were also expressed as the percentage of area occupied by these fibers, a better estimate of muscle volume occupied by the different types of fibers in muscle. In CT group, this parameter was found lower in type I fibers (31.9 \pm $14.0 \%$ in the CT group vs. $38.0 \pm 11.4 \%$ in controls, p=0.044, ES: 0.28 [0.01; 0.55]), similar in type IIA fibers $(52.4 \pm 11.2 \%$ in the CT group vs. $51.3 \pm 9.5 \%$ in controls, $\mathrm{p}=0.77, \mathrm{ES}: 0.04[-0.23 ; 0.31])$ and tended to be higher in type IIX fibers $(15.7 \pm 10.3 \%$ in the CT group vs. $10.7 \pm 9.6 \%$ in controls, $\mathrm{p}=0.051$, ES: -0.27 [-0.54; 0.00]). Overall mean fiber CSA index was lower in CT group compared to controls 
$(\mathrm{p}<0.001$, ES: 0.58 [0.31; 0.85], -20\%) (Figure 2). This lower muscle fiber area was found in type I $(\mathrm{p}<0.001$, ES: 0.76 [0.49; 1.03], -21\%), type IIA (p=0.001, ES: 0.46 [0.19; 0.73], -17\%), and type IIX fibers ( $\mathrm{p}=0.013$, ES: 0.39 [0.09; 0.69], $-16 \%$ ) of CT individuals. In CT males compared to control males, CSA was found lower in overall mean index $(\mathrm{p}=0.004,-27 \%)$, in type I fibers $(\mathrm{p}<0.001,-30 \%)$, IIA fibers $(\mathrm{p}=0.019,-22 \%)$, and IIX fibers $(\mathrm{p}=0.025,-26 \%)$. In CT females, CSA was found significantly lower in overall mean index $(\mathrm{p}=0.017,-16 \%)$ and type I fibers $(\mathrm{p}=0.008,-12 \%)$, but did not reach significance in type IIA fibers $(\mathrm{p}=0.13,-16 \%)$ and IIX fibers $(\mathrm{p}=0.36,-21 \%)$ (Table 1$)$.

\section{IMTG storage, glycogen storage, and COx histological enzyme activity}

IMTG was lower in the CT group compared to controls in overall index ( $\mathrm{p}=0.014, \mathrm{ES}: 0.34$ [0.07; 0.62], $-17 \%$ ), type I fibers ( $\mathrm{p}=0.002$, ES: $0.44[0.18 ; 0.70],-17 \%)$, and type IIA fibers $(\mathrm{p}=0.048$, ES: 0.27 [0.00; 0.53], -14\%) (Figure 3). In CT females compared to control females, IMTG was found lower in overall index ( $\mathrm{p}=0.049$, ES: 0.40 [0.00; 0.80], -21\%) and type I fibers ( $\mathrm{p}=0.010$, ES: 0.53 [0.14; 0.92], $20 \%$ ) but not significantly in type IIA fibers ( $\mathrm{p}=0.11$, ES: 0.32 [-0.07; 0.71], -22\%). In CT males, pvalues were not found $<0.05$ in overall index ( $\mathrm{p}=0.39$, ES: $0.17[-0.22 ; 0.56],-9 \%)$, type I fibers $(\mathrm{p}=0.15$, ES: $0.27[-0.11 ; 0.64],-12 \%)$ and type IIA fibers ( $p=0.65$, ES: $0.08[-0.29 ; 0.46],-5 \%)$. Glycogen content was lower in CT group compared to controls, in type I (p=0.008, ES: 0.37 [0.10; 0.63], -6\%) and IIA fibers $(\mathrm{p}=0.015$, ES: $0.33[0.07 ; 0.60],-5 \%)$. A trend was observed in glycogen overall index ( $\mathrm{p}=0.071$, ES: 0.25 [-0.02; 0.52], -2\%). Compared to control females, CT females had a lower glycogen content in overall index $(\mathrm{p}=0.023$, ES: 0.47 [0.07; 0.87], -8\%), type I fibers $(\mathrm{p}=0.034$, ES: 0.43 [0.04; 0.83], $-8 \%$ ), and type IIA fibers ( $\mathrm{p}=0.045$, ES: 0.41 [0.01; 0.81], -7\%). In CT males, glycogen content was lower in type I ( $\mathrm{p}=0.048$, ES: 0.38 [0.00; 0.75], -6\%) and type IIA ( $\mathrm{p}=0.077$, ES: 0.34 [-0.04; 0.71], $-4 \%$ ) fibers but similar in overall index ( $\mathrm{p}=0.40$, ES: $0.16[-0.23 ; 0.55],+1 \%)$. COx activity histologically measured was found similar between CT and control groups in overall index, type I fibers and type IIA fibers (Table 1). 


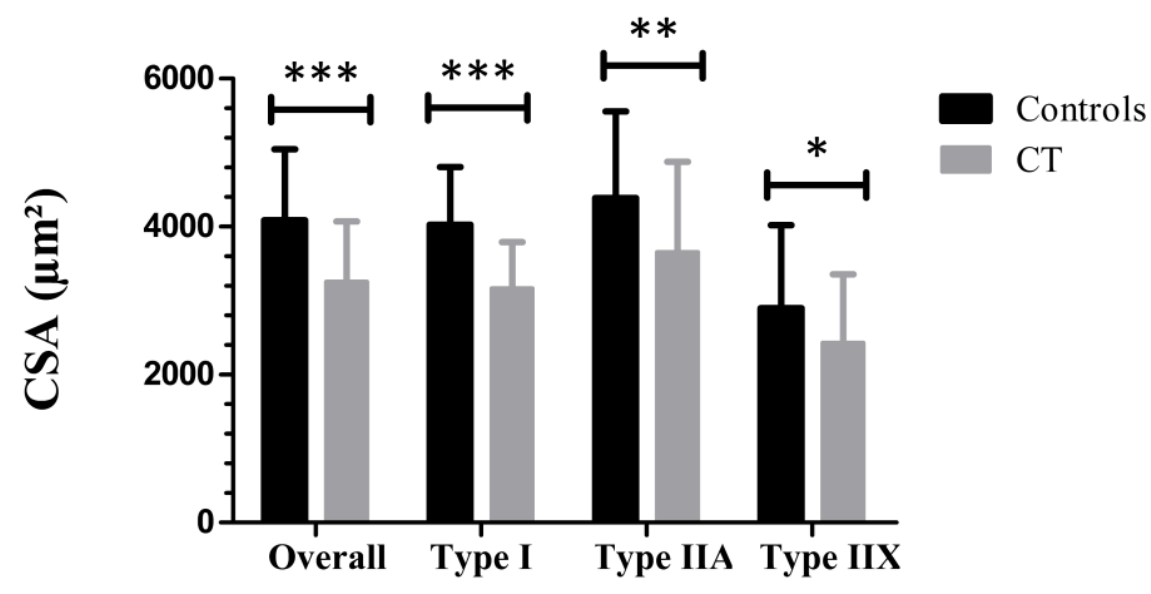

CSA: cross-sectional area; CT: subjects with constitutional thinness $-* \mathrm{p}<0.05, * * \mathrm{p}<0.01, * * * \mathrm{p}<0.001$

Figure 2: Cross-sectional areas of muscle fibers in controls $(\mathrm{n}=31)$ and subjects with constitutional thinness $(n=30)$ at baseline

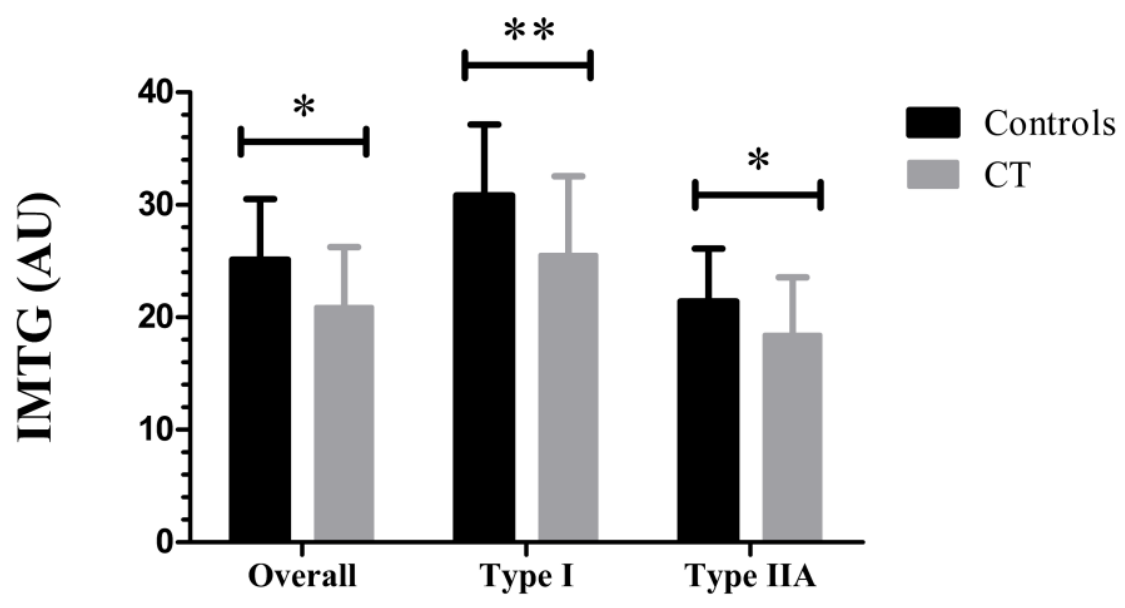

AU: arbitrary unit; CT: subjects with constitutional thinness; IMTG: intramuscular triglycerides $-* \mathrm{p}<0.05, * * \mathrm{p}<0.01$

Figure 3: Intramuscular triglycerides content in controls $(n=31)$ and subjects with constitutional thinness $(\mathrm{n}=30)$ at baseline 
Table 1: Characteristics of the population, fiber type distribution, cross-sectional areas, intramuscular triglycerides content, glycogen content and cytochrome C oxidase activity at baseline

\begin{tabular}{|c|c|c|c|c|c|c|c|c|c|c|c|}
\hline & \multicolumn{3}{|c|}{ Controls } & \multicolumn{3}{|c|}{ CT } & \multicolumn{5}{|c|}{ Multivariable Analysis } \\
\hline & \multirow{2}{*}{$\begin{array}{c}\text { Females } \\
(n=16)\end{array}$} & \multirow{2}{*}{$\begin{array}{l}\text { Males } \\
(n=15)\end{array}$} & \multirow{2}{*}{$\begin{array}{c}\text { Total } \\
(\mathbf{n}=\mathbf{3 1})\end{array}$} & \multirow{2}{*}{$\begin{array}{c}\text { Females } \\
(n=15)\end{array}$} & \multirow{2}{*}{$\begin{array}{l}\text { Males } \\
(n=15)\end{array}$} & \multirow{2}{*}{$\begin{array}{c}\text { Total } \\
(\mathbf{n}=\mathbf{3 0})\end{array}$} & \multirow{2}{*}{$\begin{array}{l}\text { Group Effect } \\
\text { p-valueHedges' } g\end{array}$} & \multicolumn{2}{|c|}{ Sex Effect } & \multicolumn{2}{|c|}{ Group $\times$ Sex } \\
\hline & & & & & & & & p-value & Hedges' $\mathrm{g} \quad \mathrm{p}$ & p-value & Hedges' g \\
\hline Age (years) & $22.4 \pm 2.8$ & $23.9 \pm 2.9$ & $23.1 \pm 2.9$ & $27.4 \pm 4.6^{c}$ & $23.6 \pm 3.8$ & $25.5 \pm 4.5$ & $0.018-0.31[-0.57 ;-0.06]$ & 0.24 & $-0.15[-0.41 ; 0.10]$ & 0.006 & $0.37[0.11 ; 0.62]$ \\
\hline Height (m) & $1.65 \pm 0.06$ & $1.80 \pm 0.07$ & $1.73 \pm 0.10$ & $1.61 \pm 0.06$ & $1.76 \pm 0.04^{\mathrm{a}}$ & $1.68 \pm 0.09$ & $0.013 \quad 0.33[0.07 ; 0.58]$ & $<0.001$ & $1.22[0.97 ; 1.48]$ & 0.80 & $0.03[-0.22 ; 0.29]$ \\
\hline Weight (kg) & $2.9 \pm 4.8$ & $74.8 \pm 7.3$ & $68.6 \pm 8.5$ & $2.8 \pm 4.5^{c}$ & $53.8 \pm 2.9^{\mathrm{c}}$ & $48.3 \pm 6.7$ & $<0.001 \quad 1.71[1.45 ; 1.97]$ & $<0.001$ & $1.10[0.84 ; 1.36]$ & .85 & $0.03[-0.23 ; 0.28]$ \\
\hline $\mathrm{BMI}\left(\mathrm{kg} \cdot \mathrm{m}^{-2}\right)$ & $.0 \pm 1.1$ & $23.0 \pm 1.2$ & $23.0 \pm 1.1$ & $16.5 \pm 0.8^{c}$ & $17.4 \pm 0.8^{c}$ & $17.0 \pm 0.9$ & $<0.001 \quad 2.63[2.37 ; 2.88]$ & 0.088 & $0.22[-0.03 ; 0.48]$ & 0.13 & $-0.20[-0.46 ; 0.06]$ \\
\hline PAL & $1.72 \pm 0.18$ & $1.81 \pm 0.26$ & $1.76 \pm 0.22$ & $60 \pm 0.22$ & $1.55 \pm 0.24^{b}$ & $1.57 \pm 0.22$ & $0.006 \quad 0.37[0.11 ; 0.63]$ & 0.76 & $0.04[-0.22 ; 0.30]$ & 0.11 & $0.21[-0.05 ; 0.47]$ \\
\hline $\mathrm{FM}(\%)$ & $1.6 \pm 4.0$ & $20.9 \pm 6.4$ & $26.4 \pm 7.5$ & $3.3 \pm 2.9^{c}$ & $15.5 \pm 2.3^{\mathrm{a}}$ & $19.4 \pm 4.8$ & $<0.001 \quad 0.69[0.43 ; 0.95]$ & $<0.001$ & $-1.11[-1.37 ;-0.85]$ & 0.55 & $-0.08[-0.34 ; 0$ \\
\hline Total FM (kg) & $6 \pm 3.3$ & $16.4 \pm 5.9$ & $8.6 \pm 5.1$ & $10.6 \pm 1.7^{\mathrm{c}}$ & $8.8 \pm 1.5^{\mathrm{b}}$ & $9.7 \pm 1.8$ & $<0.001 \quad 1.02[0.76 ; 1.28]$ & 0.001 & $-0.45[-0.71 ;-0.19]$ & 0.40 & $-0.11[-0.37 ; 0.15]$ \\
\hline Total 1 & $1 \pm 3.5$ & $58.1 \pm 6.0$ & $49.8 \pm$ & $32.8 \pm 3.3^{c}$ & $45.3 \pm 2.2^{c}$ & $39.1 \pm 6.9$ & $<0.001 \quad 1.17[0.92 ; 1.43]$ & $<0.001$ & $1.79[1.53 ; 2.05]$ & 0.29 & $0.14[-0.12 ; 0.40]$ \\
\hline Right leg lean mass $(\mathrm{kg})$ & $8 \pm 0.5$ & $9.3 \pm 1.1$ & $8.0 \pm 1.5$ & $4.7 \pm 0.6^{\mathrm{c}}$ & $6.7 \pm 0.5^{\mathrm{c}}$ & $5.7 \pm 1.2$ & $<0.001 \quad 1.37[1.12 ; 1.63]$ & $<0.001$ & $1.54[1.28 ; 1.80]$ & 0.56 & $0.08[-0.18 ; 0.33]$ \\
\hline \multicolumn{12}{|c|}{ Fiber type distribution (\%) } \\
\hline Type I & $39.4 \pm 7.4$ & $36.3 \pm 12.0$ & & & $28.0 \pm 5.8^{0.056}$ & & $0.21[-0.05 ; 0.47]$ & 0.027 & $-0.29[-0.55 ;-0.04]$ & 0.75 & $0.04[-0.22 ; 0.30]$ \\
\hline & & 47.2 & 0 & $44.3 \pm$ & $47.7 \pm$ & & 0.21 & 0.66 & & & \\
\hline Type IIX & & $16.5=$ & .4 & 3.2 & $24.3 \pm 11$ & & $0.033-0.28$ & 0.11 & & 0.9 & \\
\hline \multicolumn{12}{|l|}{$\operatorname{CSA}\left(\mu m^{2}\right)$} \\
\hline Overall & $3490 \pm 478$ & $4819 \pm 898$ & $4086 \pm 960$ & $2931 \pm 471^{\mathrm{a}}$ & $3515 \pm 952^{b}$ & & & $<0.001$ & & 0.15 & \\
\hline Type I & 156 & 4414 & 4028 & $3278 \pm$ & $3077 \pm$ & & $001 \quad 0.76$ & 0.034 & & 6 & \\
\hline Type IIA & 596 & $5301 \pm 1057$ & $4385 \pm 1172$ & $3043 \pm 556$ & $4149 \pm 1389$ a & $3658 \pm$ & $0.001 \quad 0.46[0.19 ; 0.73]$ & $<0.001$ & & 0.36 & 40] \\
\hline Type IIX & & $3872 \pm 829$ & & & $2858 \pm 833^{\mathrm{a}}$ & & & $<0.001$ & & & \\
\hline \multicolumn{12}{|l|}{ IMTG content $(\mathrm{AU})$} \\
\hline Overall & & $22.7 \pm 6.0$ & $: 1>5$ & & $20.6 \pm 4.8$ & $20.9 \pm 5.3$ & $0.34[0.07 ; 0.62]$ & 0.087 & $-0.24[-0.51 ; 0.04]$ & 0.28 & $-0.15[-0.4$ \\
\hline Type I & & $28.0 \pm 6.5$ & 6.3 & & $24.6 \pm 6.6$ & & $0.44[0.18 ; 0.70]$ & 0.031 & $-0.29[-0.56 ;-0.03]$ & 0.41 & $-0.37 ; 0.16]$ \\
\hline Type IIA & & $20.3 \pm 5.5$ & & & $19.3 \pm 4.6$ & & $0.27[0.00 ; 0.53]$ & 0.83 & $0.23]$ & 0.31 & ;0.13] \\
\hline \multicolumn{12}{|l|}{ Glycogen content (AU) } \\
\hline Overall & & $84.2 \pm 12.0$ & & & $84.9 \pm 13.5$ & & $0.25[-0.02 ; 0.52]$ & 0.001 & & 0.89 & $-0.02[-0.29 ; 0.25]$ \\
\hline Type I & & $80.3 \pm$ & & & $75.2 \pm 12.9^{\mathrm{a}}$ & & & 0.001 & & 0.42 & $0.16 ; 0.37]$ \\
\hline Type IIA & $84.1 \pm 8.2$ & $92.2 \pm 15.3$ & $88.0 \pm 12.6$ & $8.4 \pm 9.5^{\mathrm{a}}$ & $88.2 \pm 14.2^{0.077}$ & $83.8 \pm 13.1$ & $0.33[0.07 ; 0.60]$ & 0.004 & $0.40[0.14 ; 0.67]$ & 0.75 & $0.04[-0.22 ; 0.31]$ \\
\hline \multicolumn{12}{|l|}{ COx activit } \\
\hline Overall & & 101.7 & & & 8 & & .32 & 0.54 & & 0.4 & \\
\hline Type I & & $113.9 \pm 18.4$ & & & $119.1 \pm 17.0$ & & $-0.19[-0.45 ; 0.08]$ & 0.77 & $0.04[-0.23 ; 0.31]$ & 0.98 & $0.00[-0.27 ; 0.26]$ \\
\hline Type IIA & $91.9 \pm 9.4$ & $99.5 \pm 16.9$ & $95.6 \pm 13.9$ & $92.2 \pm 10.5$ & $101.4 \pm 10.2$ & $97.3 \pm 11.2$ & $0.72-0.05[-0.31 ; 0.22]$ & 0.013 & $0.34[0.07 ; 0.61]$ & 0.61 & $-0.07[-0.33 ; 0.20]$ \\
\hline
\end{tabular}

BMI: body mass index; COx: cytochrome C oxidase; CSA: cross-sectional area; CT: subjects with constitutional thinness; FM: fat mass; IMTG: intramuscular triglycerides; PAL: physical activity

level

${ }^{\mathrm{a}} \mathrm{p}<0.05,{ }^{\mathrm{b}} \mathrm{p}<0.01,{ }^{\mathrm{c}} \mathrm{p}<0.001$ between controls and subjects with constitutional thinness, within gender, from multivariable analysis 


\section{Capillary supply and enzyme activity}

As displayed in Table 2, capillary density was not found different between $\mathrm{CT}$ and control groups. C/F ratio was lower in CT subjects compared to controls (p<0.001, ES: 0.64 [0.36; 0.91], -19\%). CC was found lower in CT group in type I ( $p<0.001$, ES: 0.65 [0.38; 0.91], -18\%), type IIA ( $\mathrm{p}=0.002$, ES: 0.44 $[0.17 ; 0.71],-16 \%)$ and type IIX fibers (p=0.008, ES: $0.42[0.11 ; 0.72],-10 \%)$. CC taking into account SF, a better estimate of capillary supply, was also found lower in all fiber types of CT individuals (Table 2). CFPE was found lower in the CT group in type I ( $\mathrm{p}=0.026$, ES: $0.31[0.04 ; 0.58],-7 \%)$ and type IIA fibers ( $\mathrm{p}=0.024$, ES: 0.31 [0.04; 0.58], $-8 \%$ ) but not in type IIX (p=0.21, ES: 0.19 [-0.11;0.49], -4\%). CAFA was not found different in any of the muscle fiber types. In CT group, CS and MK activities were both found $18 \%$ lower compared to controls (respectively $\mathrm{p}=0.010$, ES: $0.36[0.09 ; 0.62]$ and $\mathrm{p}=0.009$, ES: $0.37[0.10 ; 0.65])$. Trends toward a higher CII activity (p=0.078, ES: $-0.26[-0.56 ; 0.03],+4 \%)$ and lower CK activity ( $\mathrm{p}=0.076$, ES: 0.25 [-0.03; 0.52], $-5 \%$ ) were observed in CT group. $\beta$-HAD, ENO, CIV, and LDH activities were found similar between groups. In all muscle analyses at baseline, no Group $\times$ Sex interactions were observed. Analysis of correlations between enzyme activities and energy storage in CT group and control group are detailed in Figure 4. CS activity was positively correlated with IMTG overall index $(\mathrm{R}=0.41$ and $\mathrm{p}=0.033)$ and with IMTG in type IIA fibers $(\mathrm{R}=0.59$ and $\mathrm{p}<0.001)$ in the control group whereas in CT, CS was correlated with glycogen overall content $(\mathrm{R}=0.52$ and $\mathrm{p}=0.009)$, with glycogen in type I fibers $(\mathrm{R}=0.65$ and $\mathrm{p}<0.001)$, and with glycogen in type IIA fibers $(\mathrm{R}=0.45$ and $\mathrm{p}=0.027)$. In the control group, $\mathrm{CS}$ was found positively correlated with COx activity in type IIA fibers $(\mathrm{R}=0.38, \mathrm{p}=0.040)$ and tended to be with overall COx activity $(\mathrm{R}=0.34, \mathrm{p}=0.081)$. ENO activity was negatively correlated with COx overall activity $(R=-0.42, p=0.026)$ (Figure 4$)$ in controls. In CT group, ENO was positively correlated with overall COx activity $(\mathrm{R}=0.41$ and $\mathrm{p}=0.045)$, tended to be with type I fibers COx activity $(\mathrm{R}=0.39, \mathrm{p}=0.062)$, and was significantly correlated with type IIA fibers COx activity $(\mathrm{R}=0.63$ and $\mathrm{p}<0.001)$. Glycogen overall content was also correlated with $\mathrm{COx}$ activity in type IIA fibers $(\mathrm{R}=0.46, \mathrm{p}=0.016)$ in $\mathrm{CT}$ (Figure 4). 
Table 2: Capillary supply and enzyme activities at baseline

\begin{tabular}{|c|c|c|c|c|c|c|c|c|c|c|c|c|}
\hline & \multicolumn{3}{|c|}{ Controls } & \multicolumn{3}{|c|}{ CT } & \multicolumn{6}{|c|}{ Multivariable Analysis } \\
\hline & $\begin{array}{c}\text { Females } \\
(\mathbf{n}=16)\end{array}$ & $\begin{array}{c}\text { Males } \\
(n=15)\end{array}$ & $\begin{array}{c}\text { Total } \\
(\mathbf{n}=\mathbf{3 1})\end{array}$ & $\begin{array}{c}\begin{array}{c}\text { Females } \\
(n=15)\end{array} \\
\end{array}$ & $\begin{array}{l}\text { Males } \\
(n=15)\end{array}$ & $\begin{array}{c}\text { Total } \\
(\mathbf{n}=\mathbf{3 0})\end{array}$ & \multicolumn{2}{|c|}{ Group Effect } & \multicolumn{2}{|r|}{ Sex Effect } & \multicolumn{2}{|c|}{ Group $\times$ Sex } \\
\hline \multicolumn{4}{|c|}{ CAPILLARIZATION - Global Indexes } & & & & p-value & Hedges' g & p-value & Hedges' g & p-value & Hedges' g \\
\hline $\mathrm{CD}$ & $313.1 \pm 54.4$ & $317.5 \pm 44.5$ & $314.9 \pm 49.8$ & $299.6 \pm 58.5$ & $309.8 \pm 55.5$ & $305.2 \pm 56.0$ & 0.32 & $0.14[-0.14 ; 0.42]$ & 0.46 & $0.10[-0.17 ; 0.38]$ & 0.49 & $-0.10[-0.37 ; 0.18]$ \\
\hline $\mathrm{C} / \mathrm{F}$ & $1.08 \pm 0.18$ & $1.50 \pm 0.34$ & $1.25 \pm 0.33$ & $0.90 \pm 0.18^{\mathrm{a}}$ & $1.10 \pm 0.25^{\mathrm{b}}$ & $1.01 \pm 0.24$ & $<0.001$ & $0.64[0.36 ; 0.91]$ & $<0.001$ & $0.70[0.42 ; 0.98]$ & 0.40 & $0.12[-0.16 ; 0.39]$ \\
\hline \multicolumn{13}{|c|}{ CAPILLARIZATION - Local Indexes } \\
\hline \multicolumn{13}{|c|}{ TYPE I FIBER } \\
\hline $\mathrm{CC}$ & $3.73 \pm 0.51$ & $4.41 \pm 0.71$ & $4.05 \pm 0.69$ & $3.20 \pm 0.63^{\mathrm{a}}$ & $3.45 \pm 0.69^{b}$ & $3.34 \pm 0.67$ & $<0.001$ & $0.65[0.38 ; 0.91]$ & 0.001 & $0.45[0.19 ; 0.72]$ & 0.81 & $0.03[-0.24 ; 0.30]$ \\
\hline $\mathrm{CC}$ with SF & $1.26 \pm 0.22$ & $1.60 \pm 0.33$ & $1.42 \pm 0.32$ & $1.06 \pm 0.23$ a & $1.20 \pm 0.28^{b}$ & $1.13 \pm 0.26$ & $<0.001$ & $0.65[0.38 ; 0.91]$ & $<0.001$ & $0.54[0.27 ; 0.81]$ & 0.82 & $0.03[-0.24 ; 0.30]$ \\
\hline $\mathrm{CFPE}(\mathrm{CC} / \mathrm{Pe})\left(10^{-3}\right)$ & $16.17 \pm 2.06$ & $17.14 \pm 1.50$ & $16.62 \pm 1.86$ & $14.74 \pm 2.49$ & $16.05 \pm 2.07^{0.083}$ & $15.46 \pm 2.32$ & 0.026 & $0.31[0.04 ; 0.58]$ & 0.027 & $0.31[0.04 ; 0.57]$ & 0.50 & $-0.09[-0.36 ; 0.18]$ \\
\hline CAFA (CC/CSA $)\left(10^{-3}\right)$ & $1.10 \pm 0.19$ & $1.04 \pm 0.14$ & $1.07 \pm 0.17$ & $1.08 \pm 0.20$ & $1.18 \pm 0.21$ & $1.14 \pm 0.21$ & 0.15 & $-0.20[-0.47 ; 0.07]$ & 0.82 & $0.03[-0.24 ; 0.30]$ & 0.21 & $-0.17[-0.44 ; 0.10]$ \\
\hline \multicolumn{13}{|l|}{ TYPE IIA FIBER } \\
\hline $\mathrm{CC}$ & $3.30 \pm 0.64$ & $4.51 \pm 0.80$ & $3.87 \pm 0.94$ & $2.79 \pm 0.48$ & $3.62 \pm 0.63^{b}$ & $3.25 \pm 0.70$ & 0.002 & $0.44[0.17 ; 0.71]$ & $<0.001$ & $0.76[0.50 ; 1.03]$ & 0.37 & $0.12[-0.15 ; 0.39]$ \\
\hline CC with SF & $1.10 \pm 0.24$ & $1.62 \pm 0.34$ & $1.34 \pm 0.39$ & $0.91 \pm 0.16$ & $1.28 \pm 0.26^{\mathrm{a}}$ & $1.11 \pm 0.29$ & 0.003 & $0.42[0.16 ; 0.69]$ & $<0.001$ & $0.84[0.57 ; 1.10]$ & 0.42 & $0.11[-0.16 ; 0.38]$ \\
\hline CFPE (CC/Pe) $\left(10^{-3}\right)$ & $14.23 \pm 1.87$ & $15.87 \pm 2.33$ & $14.99 \pm 2.22$ & $12.78 \pm 2.09$ & $14.55 \pm 1.49^{0.059}$ & $13.76 \pm 1.96$ & 0.024 & $0.31[0.04 ; 0.58]$ & 0.002 & $0.45[0.18 ; 0.72]$ & 0.74 & $-0.04[-0.31 ; 0.22]$ \\
\hline CAFA (CC/CSA) $\left(10^{-3}\right)$ & $0.99 \pm 0.14$ & $0.88 \pm 0.15$ & $0.94 \pm 0.15$ & $0.97 \pm 0.19$ & $0.93 \pm 0.15$ & $0.95 \pm 0.17$ & 0.96 & $-0.01[-0.28 ; 0.26]$ & 0.17 & $-0.19[-0.46 ; 0.08]$ & 0.16 & $-0.19[-0.46 ; 0.08]$ \\
\hline \multicolumn{13}{|l|}{ TYPE IIX FIBER } \\
\hline $\mathrm{CC}$ & $2.24 \pm 0.46$ & $2.84 \pm 0.40$ & $2.46 \pm 0.52$ & $1.85 \pm 0.47$ & $2.47 \pm 0.52^{\mathrm{a}}$ & $2.21 \pm 0.58$ & 0.008 & $0.42[0.11 ; 0.72]$ & $<0.001$ & $0.64[0.34 ; 0.94]$ & 0.94 & $-0.01[-0.31 ; 0.29]$ \\
\hline CC with SF & $0.72 \pm 0.16$ & $0.98 \pm 0.14$ & $0.81 \pm 0.19$ & $0.59 \pm 0.16$ & $0.82 \pm 0.20^{\mathrm{a}}$ & $0.73 \pm 0.21$ & 0.007 & $0.43[0.12 ; 0.73]$ & $<0.001$ & $0.69[0.39 ; 0.99]$ & 0.79 & $0.04[-0.26 ; 0.34]$ \\
\hline $\mathrm{CFPE}(\mathrm{CC} / \mathrm{Pe})\left(10^{-3}\right)$ & $11.80 \pm 1.54$ & $11.51 \pm 1.74$ & $11.70 \pm 1.58$ & $10.79 \pm 2.22$ & $11.55 \pm 1.71$ & $11.24 \pm 1.93$ & 0.21 & $0.19[-0.11 ; 0.49]$ & 0.48 & $0.11[-0.20 ; 0.41]$ & 0.28 & $-0.16[-0.47 ; 0.14]$ \\
\hline CAFA (CC/CSA $)\left(10^{-3}\right)$ & $1.12 \pm 0.35$ & $0.76 \pm 0.15$ & $0.99 \pm 0.34$ & $1.13 \pm 0.33$ & $0.93 \pm 0.18$ & $1.01 \pm 0.27$ & 0.58 & $-0.08[-0.38 ; 0.22]$ & 0.004 & $-0.45[-0.75 ;-0.15]$ & 0.16 & $-0.21[-0.52 ; 0.09]$ \\
\hline \multicolumn{13}{|c|}{ Enzyme activities - (IU.mg protein $\left.{ }^{-1}\right)$} \\
\hline$\beta-\mathrm{HAD}\left(10^{-3}\right)$ & $198 \pm 33$ & $199 \pm 40$ & $198 \pm 36$ & $179 \pm 28$ & $186 \pm 23$ & $182 \pm 25$ & 0.11 & $0.22[-0.05 ; 0.49]$ & 0.66 & $0.06[-0.21 ; 0.33]$ & 0.83 & $-0.03[-0.30 ; 0.24]$ \\
\hline ENO & $1.50 \pm 0.22$ & $1.96 \pm 0.42$ & $1.71 \pm 0.40$ & $1.35 \pm 0.34$ & $1.86 \pm 0.33$ & $1.63 \pm 0.42$ & 0.13 & $0.21[-0.06 ; 0.48]$ & $<0.001$ & $0.77[0.50 ; 1.04]$ & 0.38 & $0.12[-0.15 ; 0.39]$ \\
\hline $\operatorname{CS}\left(10^{-3}\right)$ & $52.1 \pm 12.0$ & $55.0 \pm 13.4$ & $53.5 \pm 12.5$ & $37.0 \pm 9.5^{\mathrm{a}}$ & $49.3 \pm 16.0$ & $43.7 \pm 14.6$ & 0.010 & $0.36[0.09 ; 0.62]$ & 0.052 & $0.27[0.00 ; 0.53]$ & 0.43 & $-0.11[-0.38 ; 0.16]$ \\
\hline CII $\left(10^{-3}\right)$ & $289 \pm 22$ & $293 \pm 26$ & $291 \pm 24$ & $311 \pm 25$ & $298 \pm 16$ & $304 \pm 21$ & 0.078 & $-0.26[-0.56 ; 0.03]$ & 0.49 & $-0.10[-0.40 ; 0.19]$ & 0.36 & $0.14[-0.16 ; 0.43]$ \\
\hline & $33.5 \pm 9.0$ & $37.9 \pm 17.6$ & $35.6 \pm 13.6$ & $31.3 \pm 8.1$ & $33.0 \pm 11.9$ & $32.2 \pm 10.2$ & 0.27 & $0.15[-0.12 ; 0.42]$ & 0.35 & $0.13[-0.14 ; 0.39]$ & 0.54 & $0.08[-0.19 ; 0.35]$ \\
\hline $\operatorname{LDH}\left(10^{-3}\right)$ & $443 \pm 43$ & $414 \pm 80$ & $430 \pm 64$ & $446 \pm 55$ & $414 \pm 48$ & $428 \pm 53$ & 0.62 & $-0.07[-0.34 ; 0.21]$ & 0.052 & $-0.27[-0.54 ; 0.00]$ & 0.92 & $-0.01[-0.29 ; 0.26]$ \\
\hline MK & $1.53 \pm 0.44$ & $1.91 \pm 0.53$ & $1.70 \pm 0.51$ & $1.19 \pm 0.39^{0.067}$ & $1.56 \pm 0.43^{\mathrm{a}}$ & $1.39 \pm 0.45$ & 0.009 & $0.37[0.10 ; 0.65]$ & 0.003 & $0.42[0.15 ; 0.69]$ & 0.66 & $0.06[-0.21 ; 0.33]$ \\
\hline CK & $11.3 \pm 0.6$ & $10.6 \pm 1.4$ & $11.0 \pm 1.1$ & $10.3 \pm 1.1^{\mathrm{b}}$ & $10.5 \pm 1.4$ & $10.4 \pm 1.2$ & 0.076 & $0.25[-0.03 ; 0.52]$ & 0.40 & $-0.11[-0.39 ; 0.16]$ & 0.14 & $-0.20[-0.48 ; 0.07]$ \\
\hline$\beta$-HAD/CS ratio & $4.00 \pm 1.09$ & $3.71 \pm 0.68$ & $3.87 \pm 0.92$ & $5.02 \pm 1.15$ & $4.09 \pm 1.25$ & $4.54 \pm 1.27$ & 0.035 & $-0.29[-0.56 ;-0.02]$ & 0.062 & $-0.26[-0.53 ; 0.01]$ & 0.58 & $0.08[-0.19 ; 0.35]$ \\
\hline ENO/CS ratio & $30.4 \pm 8.3$ & $38.4 \pm 16.2$ & $34.1 \pm 13.0$ & $37.5 \pm 8.8$ & $40.2 \pm 10.6$ & $39.0 \pm 9.7$ & 0.12 & $-0.21[-0.48 ; 0.06]$ & 0.10 & $0.22[-0.04 ; 0.49]$ & 0.35 & $0.13[-0.14 ; 0.39]$ \\
\hline CIV/CII ratio $\left(10^{-3}\right)$ & $119 \pm 35$ & $140 \pm 51$ & $128 \pm 43$ & $104 \pm 28$ & $116 \pm 42$ & $111 \pm 36$ & 0.28 & $0.16[-0.13 ; 0.45]$ & 0.16 & $0.21[-0.09 ; 0.50]$ & 0.50 & $0.10[-0.20 ; 0.39]$ \\
\hline
\end{tabular}

$\beta$-HAD: $\beta$-hydroxyacyl-CoA dehydrogenase; CII and CIV: second and fourth respiratory chain complexes; CAFA: capillary contact per fiber area; CC: capillary contact; CD: capillary density;

C/F capillary to fiber ratio; CFPE: capillary to fiber-perimeter exchange; CK: creatine kinase; CS: citrate synthase; CSA: cross-sectional area; CT: subjects with constitutional thinness; ENO:

enolase; LDH: lactate dehydrogenase; MK: myokinase; Pe: Perimeter; SF: sharing factor

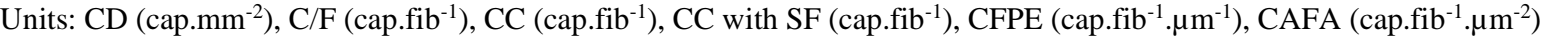

${ }^{\mathrm{a}} \mathrm{p}<0.05,{ }^{\mathrm{b}} \mathrm{p}<0.01,{ }^{\mathrm{c}} \mathrm{p}<0.001$ between controls and subjects with constitutional thinness, within gender, from multivariable analysis 


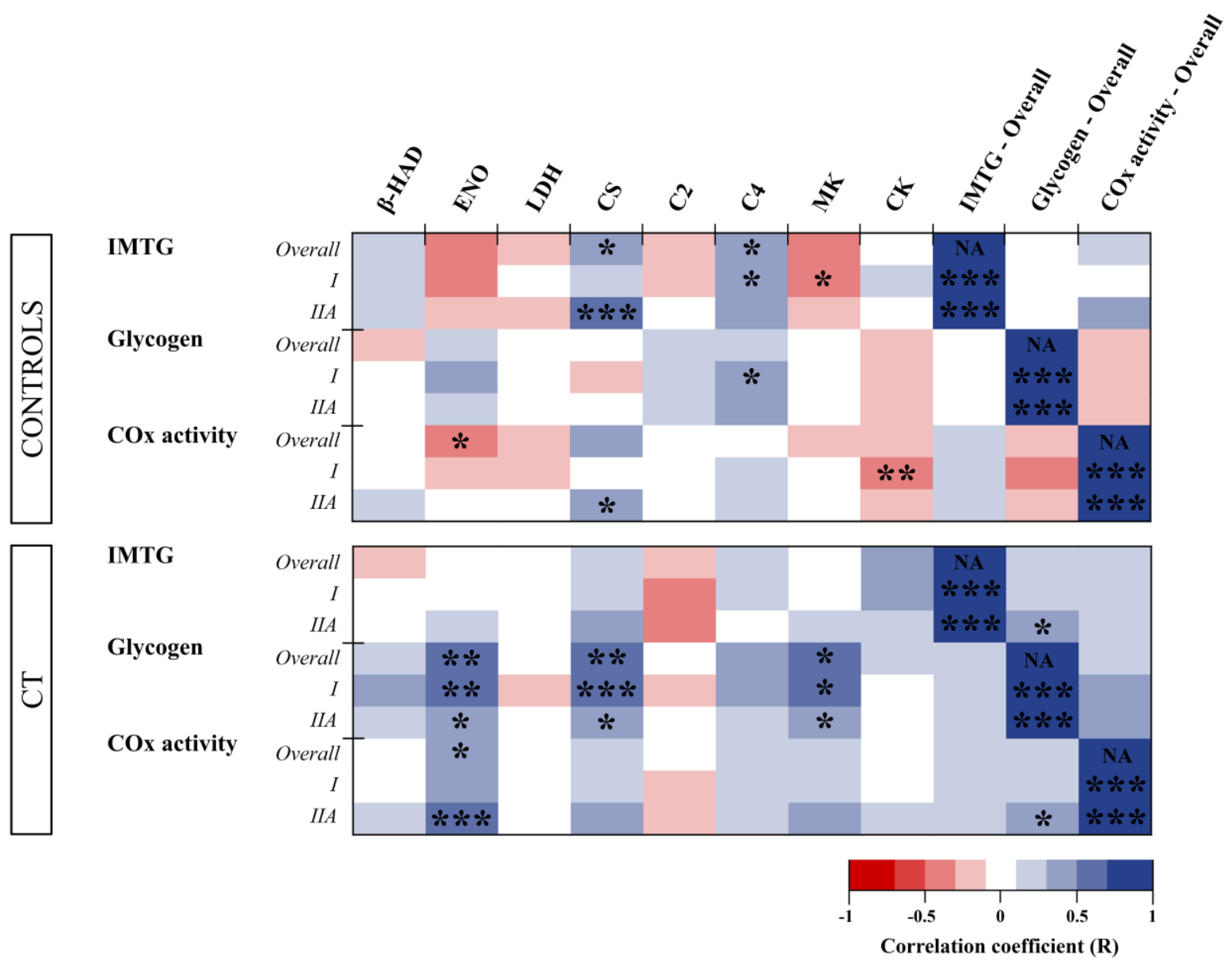

$\beta$-HAD: $\beta$-hydroxyacyl-CoA dehydrogenase; CII and CIV: second and fourth respiratory chain complexes; CK: creatine kinase; COx: cytochrome C oxidase; CS: citrate synthase; CT: subjects with constitutional thinness; ENO: enolase; IMTG: intramuscular triglycerides; LDH: lactate dehydrogenase; MK: myokinase; NA: Not Applicable (correlation within a single variable $)-* \mathrm{p}<0.05, * *<0.01, * * *<0.001$

Figure 4: Heatmap of correlations between intramuscular triglycerides, glycogen content, cytochrome

C oxidase activity, and enzyme assessments in controls $(\mathrm{n}=31)$ and subjects with constitutional thinness $(\mathrm{n}=30)$ at baseline 


\section{Effect of overfeeding}

After 2 weeks of overfeeding, both control and CT groups gained weight $(\mathrm{p}<0.001,68.6 \pm 8.5 \mathrm{~kg}$ pre vs. $69.4 \pm 9.5 \mathrm{~kg}$ post-overfeeding in controls and $\mathrm{p}<0.001,48.3 \pm 6.7 \mathrm{~kg}$ pre vs. $48.5 \pm 6.5 \mathrm{~kg}$ postoverfeeding in CT individuals, $\mathrm{p}=0.23$, ES: -0.12 [-0.31; 0.07], for Group $\times$ Time interaction) (Table 3). CSA of each muscle fibers was found unchanged in response to overfeeding in both groups. For IMTG indexes, no GroupxTime interactions were observed. Yet, the mixed model showed an increase in IMTG of CT group in overall index ( $\mathrm{p}=0.001$, ES: $0.47[0.19,0.75],+11 \%)$, type I fibers $(\mathrm{p}=0.004$; ES: 0.40 $[0.13 ; 0.68],+10 \%)$ and type IIA fibers (p=0.007, ES: $0.38[0.11 ; 0.65],+9 \%)$. All indexes of IMTG were found unchanged in the control group. Glycogen content, COx activity, and capillary supply were found unchanged with overfeeding for all indexes in both control and CT groups, except for C/F ratio (see Table 3). Statistical analysis of CII and CIV enzyme activities showed an absence of significance in Group $\times$ Time interaction for CII activity, and a trend for CIV activity ( $\mathrm{p}=0.078$, ES: 0.18 [-0.02; 0.38]). Yet, CT group tended to increase CII activity ( $\mathrm{p}=0.054$, ES: $0.31[0.00 ; 0.62],+5 \%)$ and CIV activity ( $\mathrm{p}=0.052$, ES: $0.29[0.00 ; 0.58],+17 \%)$ whereas CII and CIV activities were found unchanged in control group. No effects of overfeeding were observed for $\beta$-HAD, ENO, CS, LDH, MK and CK enzyme activities in both groups. 
Table 3: Effect of overfeeding

\begin{tabular}{|c|c|c|c|c|c|c|}
\hline & \multicolumn{2}{|c|}{ Controls } & \multicolumn{2}{|c|}{ CT } & \multicolumn{2}{|c|}{ Mixed model } \\
\hline & $\begin{array}{l}\text { Pre } \\
\text { overfeeding }\end{array}$ & $\begin{array}{l}\text { Post } \\
\text { overfeeding }\end{array}$ & $\begin{array}{l}\text { Pre } \\
\text { overfeeding }\end{array}$ & Post overfeeding & \multicolumn{2}{|c|}{ Group $\times$ Time } \\
\hline \multicolumn{3}{|c|}{ Characteristics of the population } & & & p-value & Hedges'g \\
\hline Weight $(\mathrm{kg})$ & $68.6 \pm 8.5$ & $69.4 \pm 9.5^{c}$ & $48.3 \pm 6.7$ & $48.5 \pm 6.5^{c}$ & 0.23 & $-0.12[-0.31 ; 0.07]$ \\
\hline $\mathrm{BMI}\left(\mathrm{kg} \cdot \mathrm{m}^{-2}\right)$ & $23.0 \pm 1.1$ & $23.3 \pm 1.2^{c}$ & $17.0 \pm 0.9$ & $17.1 \pm 0.9^{\mathrm{c}}$ & 0.46 & $-0.07[-0.26 ; 0.12]$ \\
\hline FM $(\%)$ & $26.4 \pm 7.5$ & $26.3 \pm 6.8$ & $19.4 \pm 4.8$ & $19.2 \pm 4.8$ & 0.063 & $0.18[-0.01 ; 0.37]$ \\
\hline Total FM (kg) & $18.6 \pm 5.1$ & $18.8 \pm 5.0^{\mathrm{b}}$ & $9.7 \pm 1.8$ & $9.5 \pm 1.7^{\mathrm{a}}$ & 0.71 & $0.04[-0.15 ; 0.23]$ \\
\hline Total lean mass $(\mathrm{kg})$ & $49.8 \pm 9.4$ & $50.5 \pm 9.4^{c}$ & $39.1 \pm 6.9$ & $39.3 \pm 7.0^{\mathrm{a}}$ & 0.031 & $-0.21[-0.40 ;-0.02]$ \\
\hline \multicolumn{7}{|l|}{$\mathrm{CSA}\left(\mu \mathrm{m}^{2}\right)$} \\
\hline Overall & $4086 \pm 960$ & $3994 \pm 1163$ & $3256 \pm 818$ & $3478 \pm 766$ & 0.087 & $0.17[-0.02 ; 0.37]$ \\
\hline Type I & $4028 \pm 781$ & $3801 \pm 855$ & $3167 \pm 627$ & $3308 \pm 619$ & 0.12 & $0.15[-0.04 ; 0.35]$ \\
\hline Type IIA & $4385 \pm 1172$ & $4384 \pm 1419$ & $3658 \pm 1218$ & $3781 \pm 1076$ & 0.38 & $0.09[-0.11 ; 0.28]$ \\
\hline Type IIX & $2896 \pm 1127$ & $2727 \pm 937$ & $2434 \pm 925$ & $2368 \pm 809$ & 0.67 & $0.05[-0.17 ; 0.27]$ \\
\hline \multicolumn{7}{|l|}{ IMTG content $(\mathrm{AU})$} \\
\hline Overall & $25.1 \pm 5.4$ & $25.7 \pm 6.5$ & $20.9 \pm 5.3$ & $23.2 \pm 4.1^{b}$ & 0.16 & $0.14[-0.06 ; 0.34]$ \\
\hline Type I & $30.9 \pm 6.3$ & $31.4 \pm 6.5$ & $25.6 \pm 7.0$ & $28.2 \pm 5.8^{b}$ & 0.17 & $0.14[-0.06 ; 0.33]$ \\
\hline Type IIA & $21.4 \pm 4.7$ & $22.5 \pm 6.2$ & $18.4 \pm 5.1$ & $20.1 \pm 3.9^{b}$ & 0.30 & $0.10[-0.09 ; 0.30]$ \\
\hline \multicolumn{7}{|l|}{ Glycogen content (AU) } \\
\hline Overall & $81.0 \pm 10.3$ & $85.4 \pm 12.4$ & $79.2 \pm 13.2$ & $80.0 \pm 11.7$ & 0.57 & $-0.06[-0.25 ; 0.14]$ \\
\hline Type I & $75.1 \pm 13.6$ & $78.5 \pm 13.1$ & $70.4 \pm 12.1$ & $72.1 \pm 10.7$ & 0.85 & $-0.02[-0.21 ; 0.18]$ \\
\hline Type IIA & $88.0 \pm 12.6$ & $88.9 \pm 12.5$ & $83.8 \pm 13.1$ & $84.8 \pm 12.1$ & 0.79 & $0.03[-0.17 ; 0.22]$ \\
\hline \multicolumn{7}{|l|}{ COx activity (AU) } \\
\hline Overall & $101.1 \pm 13.3$ & $103.6 \pm 12.1$ & $104.3 \pm 11.4$ & $101.2 \pm 14.5$ & 0.20 & $-0.13[-0.33 ; 0.07]$ \\
\hline Type I & $113.1 \pm 14.1$ & $114.1 \pm 14.7$ & $118.7 \pm 15.3$ & $113.2 \pm 18.6$ & 0.16 & $-0.14[-0.34 ; 0.06]$ \\
\hline Type IIA & $95.6 \pm 13.9$ & $98.1 \pm 10.1$ & $97.3 \pm 11.2$ & $94.3 \pm 13.8$ & 0.20 & $-0.13[-0.33 ; 0.07]$ \\
\hline \multicolumn{7}{|c|}{ CAPILLARIZATION - Global Indexes } \\
\hline $\mathrm{CD}$ & $314.9 \pm 49.8$ & $307.0 \pm 66.1^{0.090}$ & $305.2 \pm 56.0$ & $307.6 \pm 58.5$ & 0.30 & $0.11[-0.09 ; 0.31]$ \\
\hline $\mathrm{C} / \mathrm{F}$ & $1.25 \pm 0.33$ & $1.23 \pm 0.39$ & $1.01 \pm 0.24$ & $1.09 \pm 0.24^{\mathrm{a}}$ & 0.041 & $0.21[0.01 ; 0.41]$ \\
\hline \multicolumn{7}{|c|}{$\begin{array}{l}\text { CAPILLARIZATION - Local Indexes } \\
\text { TYPE I FIBER }\end{array}$} \\
\hline $\mathrm{CC}$ & $4.05 \pm 0.69$ & $3.94 \pm 1.09$ & $3.34 \pm 0.67$ & $3.45 \pm 0.62$ & 0.30 & $0.10[-0.09 ; 0.30]$ \\
\hline $\mathrm{CC}$ with SF & $1.42 \pm 0.32$ & $1.41 \pm 0.48$ & $1.13 \pm 0.26$ & $1.19 \pm 0.25$ & 0.43 & $0.08[-0.12 ; 0.27]$ \\
\hline $\mathrm{CFPE}(\mathrm{CC} / \mathrm{Pe})\left(10^{-3}\right)$ & $16.62 \pm 1.86$ & $16.49 \pm 3.12$ & $15.46 \pm 2.32$ & $15.41 \pm 1.97$ & 0.68 & $0.04[-0.15 ; 0.24]$ \\
\hline $\begin{array}{l}\text { CAFA (CC/CSA) }\left(10^{-}\right. \\
3 \text { ) }\end{array}$ & $1.07 \pm 0.17$ & $1.08 \pm 0.21$ & $1.14 \pm 0.21$ & $1.09 \pm 0.17$ & 0.69 & $-0.04[-0.23 ; 0.16]$ \\
\hline \multicolumn{7}{|l|}{ TYPE IIA FIBER } \\
\hline $\mathrm{CC}$ & $3.87 \pm 0.94$ & $3.99 \pm 1.13$ & $3.25 \pm 0.70$ & $3.44 \pm 0.79$ & 0.39 & $0.09[-0.11 ; 0.28]$ \\
\hline $\mathrm{CC}$ with SF & $1.34 \pm 0.39$ & $1.43 \pm 0.48$ & $1.11 \pm 0.29$ & $1.20 \pm 0.32^{0.062}$ & 0.68 & $0.04[-0.15 ; 0.24]$ \\
\hline $\mathrm{CFPE}(\mathrm{CC} / \mathrm{Pe})\left(10^{-3}\right)$ & $14.99 \pm 2.22$ & $14.91 \pm 2.59$ & $13.76 \pm 1.96$ & $13.83 \pm 2.08$ & 0.51 & $0.07[-0.13 ; 0.26]$ \\
\hline $\begin{array}{l}\text { CAFA (CC/CSA) }\left(10^{-}\right. \\
\left.{ }^{-}\right)\end{array}$ & $0.94 \pm 0.15$ & $0.90 \pm 0.14$ & $0.95 \pm 0.17$ & $0.92 \pm 0.17$ & 0.68 & $0.04[-0.15 ; 0.24]$ \\
\hline \multicolumn{7}{|l|}{ TYPE IIX FIBER } \\
\hline $\mathrm{CC}$ & $2.46 \pm 0.52$ & $2.29 \pm 0.55^{0.093}$ & $2.21 \pm 0.58$ & $2.09 \pm 0.42$ & 0.55 & $0.07[-0.15 ; 0.29]$ \\
\hline $\mathrm{CC}$ with SF & $0.81 \pm 0.19$ & $0.77 \pm 0.20$ & $0.73 \pm 0.21$ & $0.69 \pm 0.15$ & 0.80 & $0.03[-0.19 ; 0.25]$ \\
\hline CFPE (CC/Pe) $\left(10^{-3}\right)$ & $11.70 \pm 1.58$ & $11.03 \pm 1.83^{0.085}$ & $11.24 \pm 1.93$ & $10.90 \pm 1.97$ & 0.63 & $0.05[-0.17 ; 0.27]$ \\
\hline $\begin{array}{l}\text { CAFA (CC/CSA) }\left(10^{-}\right. \\
\left.3^{2}\right)\end{array}$ & $0.99 \pm 0.34$ & $0.92 \pm 0.21$ & $1.01 \pm 0.27$ & $1.01 \pm 0.32$ & 0.87 & $0.02[-0.20 ; 0.24]$ \\
\hline \multicolumn{7}{|c|}{ Enzyme activities - (IU.mg protein ${ }^{-1}$ ) } \\
\hline$\beta$-HAD $\left(10^{-3}\right)$ & $198 \pm 36$ & $205 \pm 29$ & $182 \pm 25$ & $193 \pm 37$ & 0.77 & $0.03[-0.17 ; 0.23]$ \\
\hline ENO & $1.71 \pm 0.40$ & $1.82 \pm 0.45$ & $1.63 \pm 0.42$ & $1.76 \pm 0.71$ & 0.92 & $0.01[-0.19 ; 0.21]$ \\
\hline $\operatorname{CS}\left(10^{-3}\right)$ & $53.5 \pm 12.5$ & $57.6 \pm 18.3$ & $43.7 \pm 14.6$ & $46.4 \pm 14.8$ & 0.93 & $-0.01[-0.21 ; 0.19]$ \\
\hline CII $\left(10^{-3}\right)$ & $291 \pm 24$ & $299 \pm 40$ & $304 \pm 21$ & $317 \pm 30^{0.054}$ & 0.51 & $0.07[-0.14 ; 0.29]$ \\
\hline $\operatorname{CIV}\left(10^{-3}\right)$ & $35.6 \pm 13.6$ & $33.3 \pm 10.5$ & $32.2 \pm 10.2$ & $37.7 \pm 12.8^{0.052}$ & 0.078 & $0.18[-0.02 ; 0.38]$ \\
\hline LDH $\left(10^{-3}\right)$ & $430 \pm 64$ & $437 \pm 66$ & $428 \pm 53$ & $430 \pm 53$ & 0.67 & $-0.04[-0.25 ; 0.16]$ \\
\hline MK & $1.70 \pm 0.51$ & $1.86 \pm 0.63$ & $1.39 \pm 0.45$ & $1.46 \pm 0.60$ & 0.57 & $-0.06[-0.26 ; 0.14]$ \\
\hline $\mathrm{CK}$ & $11.0 \pm 1.1$ & $11.4 \pm 1.1$ & $10.4 \pm 1.2$ & $10.8 \pm 1.4$ & 0.95 & $0.01[-0.19 ; 0.21]$ \\
\hline$\beta$-HAD/CS ratio & $3.87 \pm 0.92$ & $3.93 \pm 1.42$ & $4.54 \pm 1.27$ & $4.40 \pm 1.04$ & 0.72 & $-0.04[-0.24 ; 0.16]$ \\
\hline ENO/CS ratio & $34.1 \pm 13.0$ & $34.5 \pm 13.0$ & $39.0 \pm 9.7$ & $39.6 \pm 13.7$ & 0.69 & $-0.04[-0.24 ; 0.16]$ \\
\hline CIV/CII ratio $\left(10^{-3}\right)$ & $128 \pm 43$ & $116 \pm 37$ & $111 \pm 36$ & $123 \pm 36$ & 0.15 & $0.16[-0.06 ; 0.38]$ \\
\hline
\end{tabular}

$\beta$-HAD: $\beta$-hydroxyacyl-CoA dehydrogenase; BMI: body mass index; CII and CIV: second and fourth respiratory chain complexes; CAFA: capillary contact per fiber area; CC: capillary contact; $\mathrm{CD}$ : capillary density; $\mathrm{C} / \mathrm{F}$ capillary to fiber ratio; CFPE: capillary to fiber-perimeter exchange; CK: creatine kinase; COx: cytochrome C oxidase; CS: citrate synthase; CSA: cross-sectional area; CT: subjects with constitutional thinness; ENO: enolase; FM: fat mass; IMTG: intramuscular triglycerides; LDH: lactate dehydrogenase; MK: myokinase; Pe: Perimeter; SF: sharing factor; Units: CD (cap.mm $\left.\mathrm{mm}^{-2}\right), \mathrm{C} / \mathrm{F}$ (cap.fib $\left.{ }^{-1}\right)$, CC (cap.fib $\left.{ }^{-1}\right)$, CC with SF (cap.fib $\left.{ }^{-1}\right)$, CFPE (cap.fib $\left.{ }^{-1} \cdot \mu m^{-1}\right)$, CAFA (cap.fib $\left.{ }^{-1} \cdot \mu m^{-2}\right)$; ${ }^{a} p<0.05,{ }^{b} p<0.01,{ }^{c} p<0.001$ between pre and post-overfeeding within controls and subjects with constitutional thinness, from mixed model analysis 


\section{Discussion}

The main objective of the present study was to investigate muscle energy substrates and muscle phenotype of CT subjects compared to control ones, at baseline and in response to overfeeding. The present work seems to be the first to report low IMTG stores in CT. Individuals with CT presented lower IMTG stores for overall index $(\mathrm{p}=0.014,-17 \%)$, type I $(\mathrm{p}=0.002,-17 \%)$, and type IIA $(\mathrm{p}=0.048,-14 \%)$ muscle fibers, compared to controls. Moreover, CT females seemed to be more affected than CT males by this low IMTG content. Indeed, CT females showed significantly lower IMTG in overall index and type I fibers than controls (respectively $-21 \%$ and $-20 \%$ ), unlike CT males whose IMTG content was not significantly lower than controls (respectively $-9 \%$ and $-12 \%$ ). The main reason for exploring IMTG in CT was the downregulation of FITM1 and FITM2 genes previously observed (Galusca et al. 2018). FITM1 is specific to skeletal muscle whereas FITM2 is expressed in many tissues (Kadereit et al. 2008), both playing a role in the partitioning of newly synthesized triglycerides into lipids droplets (Kadereit et al. 2008). Indeed, overexpression of FITM2 results in IMTG accumulation (Miranda et al. 2011). Thus, present results are consistent with our initial hypothesis and existing literature. From these low IMTG levels observed in CT, low $\beta$-HAD enzyme activity could have been expected. Although CT subjects presented much lower values of $\beta$-HAD activity; significance was not achieved (182 \pm 25 IU.mg protein-1 in CT group vs. $198 \pm 36$ IU.mg protein-1 in controls, $\mathrm{p}=0.11,-8 \%)$, likely due to the high variability of this type of enzyme assessments. The low IMTG content of CT individuals observed for the first time here might be in agreement with their low muscle oxidative profile (Galusca et al. 2018), but should be further investigated in future works. A lower expression in CT of perilipins (PLIN) that have many different roles in the regulation of IMTG synthesis and lipid droplets growth (Morales et al. 2017) would for instance support present observations. It could also be of interest to assess AMPactivated protein kinase (AMPK), the key "fuel sensing" system playing a crucial role in the activation of fatty acid metabolism (Hardie 2004), and its signaling cascades (in particular acetyl-CoA carboxylase 
(ACC), malonyl-CoA and carnitine palmitoyltransferase-1 (CPT1) (Winder 2001; Saha and Ruderman 2003)).

On the other hand, CT participants also showed a lower glycogen content compared to controls in type $\mathrm{I}(\mathrm{p}=0.008,-6 \%)$ and IIA fibers $(\mathrm{p}=0.015,-5 \%)$, and a trend towards a lower glycogen content in overall index $(\mathrm{p}=0.071)$. This lower glycogen content was found in overall index, type I fibers and type IIA fibers for CT females (respectively $-8 \%,-8 \%$, and $-7 \%$ ), but only for type I fibers in CT males (-6\%) despite a tendency for type IIA fibers (-4\%). Clinically, these results should however be interpreted with caution since, although significant, the differences remain small. Besides, ENO enzyme of glycolysis was not found significantly lower in skeletal muscle of CT subjects. Carbohydrate supplementation and physical training that are known to impact muscle glycogen content (Hearris et al. 2018) would not, however, explain the results since CT and control participants had normal energy intakes with the same distribution of macronutrients and were all recruited without engagement in regular intense physical activity (according to the MOSPA questionnaire, and no more than 3 sessions of physical activity per week) (Ling et al. 2016, 2019). PAL, measured for the first time in CT males in the present study, was found lower compared to control males. In contrast, PAL in CT females was found similar to control females, as already reported (Bossu et al. 2007; Galusca et al. 2018). Although unexpected, these results further refute the potential implication of high energy expenditure through over-exercising in the low BMI of CT participants, since on the contrary, CT participants presented a similar PAL (females) or a lower PAL (males) compared to controls.

As a second main result, CT subjects displayed an unusual muscle phenotype. Firstly, a muscle hypotrophy was observed for all fiber types of $\mathrm{CT}$ individuals, in agreement with previous findings (Galusca et al. 2018). In CT, CSA was found $-21 \%,-17 \%$ and $-16 \%$ lower, for type I, IIA and IIX fibers respectively, with strong statistical power. Overall mean CSA was also largely lower $(<0.001,-20 \%)$ in CT. In view of the statistical results, muscle hypotrophy was even more pronounced in CT males than in CT females $(-30 \%,-22 \%,-26 \%$ and $-27 \%$ for males and $-12 \%,-16 \%,-21 \%$ and $-16 \%$ for females, in 
type I, IIA, IIX fibers and overall mean CSA respectively). This may suggest the presence of a minimum threshold in fiber size of "healthy" individuals who are not suffering from myopathy. A lower percentage of area occupied by type I fibers ( $\mathrm{p}=0.044)$ was observed in CT and fiber type composition revealed a higher percentage of type IIX fibers in CT $(\mathrm{p}=0.033)$, suggesting a low oxidative profile. Fiber distribution should however be considered with caution given the high variability in the biopsied fibers of a $150 \mathrm{mg}$ sample.

In addition, present results showed a lower capillary supply in CT. C/F ratio, a global index of capillary supply, was found lower in subjects with CT. The normal CD observed in CT group was easily explained by their low $\mathrm{C} / \mathrm{F}$ ratio which tended to decrease $\mathrm{CD}$, concomitantly with their smaller fibers that tended to increase CD. Concerning local indexes, the low capillarization of CT subjects affected all fiber types, but with a higher statistical power in type I oxidative fibers. Since capillaries are determinant factors of dioxygen and nutrients supply, present results support once more a low oxidative capacity in CT. Yet, CAFA index (CC/CSA), which reflects a supply diffusion distance, contrasted with other local indexes: no statistical differences were found between CT subjects and controls. This, therefore, raises the hypothesis that the low capillary supply observed in CT individuals might only reflect an adaptation to their small fiber size. In addition, capillaries do not only provide oxygen supply but are also implied in the control of muscle mass. Indeed, satellite cells are localized close to blood vessels and are correlated with muscle capillarization (Mounier et al. 2011). Then, it could also be relevant to explore whether satellite cells would be less abundant in CT.

CS enzyme activity was found lower in CT participants $(\mathrm{p}=0.010)$ even if no alterations of the mitochondrial respiratory chain were demonstrated here. Indeed, CIV activity determined with spectrophotometry and COx activity determined with histological methods were both found similar to controls in CT participants. A trend toward a higher CII activity $(\mathrm{p}=0.078)$ was however observed. Previous observations on the same cohort however showed a tendency toward lower first complex of the respiratory chain (CI) and CII activities using oxygraphy on fresh skeletal muscle in CT (Ling et al. 
2019), while a higher CII activity but similar CI activity compared to controls were observed in white adipose tissue (Ling et al. 2019). Further studies are needed to question mitochondrial respiration regarding these differing results. Rapid muscle regeneration of ATP was also explored in the present study and results showed a lower MK activity $(\mathrm{p}=0.009)$ and a tendency for CK activity to be low $(\mathrm{p}=0.076)$ in CT. Thus, CT people could display impairments in their anaerobic alactic metabolism involving ADP-to-ATP conversions and hydrolysis of phosphocreatine which both provide rapid regeneration of energy. Analysis of correlations also showed different profiles between CT and control groups (Figure 4). In the control group, CS activity was unsurprisingly positively correlated with IMTG storage and COx activity, and COx activity was negatively associated with ENO activity. In contrast, for CT participants, CS was positively correlated with glycogen content, and COx activity was positively associated with ENO and glycogen content. These correlations need to be interpreted with caution regarding their moderate-to-large correlation coefficients but would suggest an unusual muscle metabolic profile in CT individuals, mostly based on carbohydrate metabolic pathways to support mitochondrial oxidative activity. Although some studies suggest a similar fasting respiratory quotient at rest between CT and normal-weight individuals (Scalfi et al. 1992; Bossu et al. 2007; Marra et al. 2007, 2019; Germain et al. 2014; Galusca et al. 2018; Ling et al. 2019); this substrates utilization remains to be further questioned during daily activities and exercise. These enzyme results should be cautiously interpreted given the technical limitations: enzyme assessments were performed on homogenates of muscle samples and were therefore inevitably impacted by fiber type distribution. Yet, these homogenates are still representative of the enzyme efficiency of the whole muscle sample.

Altogether, present results suggest a low muscle oxidative profile in CT. In future investigations, it could be of major interest to question the potential downregulation of key regulators of oxidative metabolism - such as peroxisome proliferator-activated receptor-gamma coactivator-1 $\alpha$ (PGC-1 $\alpha)$ (Liang and Ward 2006) - to further explore this untypical metabolic profile in CT. 
For the first time, results showed that present overfeeding succeeded in making people with CT gain weight ( $\mathrm{p}<0.001)$. This result however needs to be interpreted with caution from a clinical point of view: CT individuals only went from $48.3 \pm 6.7 \mathrm{~kg}$ pre to $48.5 \pm 6.5 \mathrm{~kg}$ post-overfeeding. To the best of our knowledge, the present study was the first to investigate the effect of an overfeeding on skeletal muscle tissue in CT compared to controls. Based on literature, different results could have been expected. For instance, recent studies in normal-weight individuals showed contrasting results on skeletal muscle in response to 8 weeks of high-fat overfeeding. Toledo et al. observed an increase in lipid droplet content and CS mRNA expression but no changes in COx mRNA expression (Toledo et al. 2018); whereas Covington et al. observed no modifications of IMTG content (Covington et al. 2017). In the present study, normal-weight controls did not modify their IMTG stores for any of the indexes, but in contrast, CT individuals increased their IMTG in overall index $(\mathrm{p}=0.001,+11 \%)$, type I fibers $(\mathrm{p}=0.004 ;+10 \%)$ and type IIA fibers $(\mathrm{p}=0.007,+9 \%)$. If this increase might have been facilitated by their low IMTG at baseline, it remains that CT individuals showed an increase in their IMTG content. CII and CIV activities also tended to be increased in the $\mathrm{CT}$ group in response to overfeeding (respectively $\mathrm{p}=0.054,+5 \%$ and $\mathrm{p}=0.052,+17 \%$ ), which might be related to their increase in IMTG. IMTG accumulation might be associated with higher mitochondrial oxidation from lipid substrates, but it would therefore be difficult to explain the absence of an increase in both $\beta-\mathrm{HAD}$ and CS activities. CII and CIV results must be interpreted with caution given the absence of significant Group $\times$ Time interactions (respectively $\mathrm{p}=0.51$, $0.07[-0.14 ; 0.29]$ and $\mathrm{p}=0.078,0.18[-0.02 ; 0.38])$. The other analyses such as glycogen content, capillary supply, CS or COx activities, do not seem to be particularly modified by the overfeeding for either CT or control participants.

From a methodological point of view, some limitations in the present study should be considered. Food intake was recorded using self-reported $2 \times 7$-day food diaries in free-living conditions, pre and postoverfeeding (Ling et al. 2016). As previously published (Ling et al. 2020), baseline food intake was not lower in CT individuals compared to controls, and both CT and control groups increased food intake 
with overfeeding. However, food intake assessed through self-reporting (using GENI software and SUVIMAX study) is known to be subjective. More objective methods should be used in the future. In addition, the diet has been reported during the 2 nd week of overfeeding, and not during the whole period. PAL was measured by ActiHeart ${ }^{\circledR}$ providing estimations of PAL, based on its capacity to detect and quantify movements. This accelerometer is not necessarily the most accurate and appropriate to evaluate all types of physical activities and sedentary lifestyles. It probably led to underestimations of PAL, especially for spontaneous and repeated muscle contractions in daily life, such as fidgeting. Yet, literature shows a growing interest in potential implications of fidgeting in CT (Marra et al. 2007; Pasanisi et al. 2013; Germain et al. 2014), which should be more investigated in future studies.

To conclude, this was the first study that performed skeletal muscle biopsies in a large sample of both females and males with CT. The results provided evidence of low IMTG and glycogen stores, low CSA reflecting muscle hypotrophy, high proportions of type IIX fibers, low capillary supply, and specific enzyme features including a low CS activity in CT participants. Most of the results suggested a low muscle oxidative profile in $\mathrm{CT}$ that might be indicative of low aerobic capacity. In response to overfeeding, few modifications specific to CT groups were observed, except a moderate increase in IMTG, CII activity, and CIV activity, that have however to be interpreted with caution. Present findings raised the question of the functional consequences in real conditions of these histological and enzymological observations. It would be of particular interest to evaluate aerobic and anaerobic capacities, substrates oxidation, and metabolic flexibility in CT. From a clinical approach, the fact remains that $\mathrm{CT}$ individuals have a very low BMI, and physical activity combined with a diet may help people with CT gain weight. Thus, a better knowledge of CT subjects' physical abilities might make it possible to provide better care for this population. 
Acknowledgements: The authors are grateful to the volunteers for their participation and to the technicians of AME2P laboratory and LIBM.

Funding: Nestlé Institute of Health Science (NIHS) provided financial support and had a role in designing the study, conducting the research and analyzing the data.

\section{Conflict of interest: None.}

Author contributions: NG, JV, BG, DC, LF, BE, DT: Conceptualization, Resources, Visualization, Supervision, Funding acquisition. JH: Project administration, Data Curation. MB, JV, CH, ANM, FC, TT: Methodology, Validation, Investigation. BP: Formal analysis. MB, JV, DT, DC: Writing - Original Draft, Review \& Editing. 
Apfelbaum, M., and Sachet, P. 1982. [Constitutional thinness]. Rev. Prat. 32(3): 245-247.

Aubertin, E. 1953. [Treatment of constitutional thinness]. J. Med. Bord. 130(5): 676-681.

Bossu, C., Galusca, B., Normand, S., Germain, N., Collet, P., Frere, D., Lang, F., Laville, M., and Estour, B. 2007. Energy expenditure adjusted for body composition differentiates constitutional thinness from both normal subjects and anorexia nervosa. Am. J. Physiol. Endocrinol. Metab. 292(1): E132-137. doi:10.1152/ajpendo.00241.2006.

Bosy-Westphal, A., Reinecke, U., Schlörke, T., Illner, K., Kutzner, D., Heller, M., and Müller, M.J. 2004. Effect of organ and tissue masses on resting energy expenditure in underweight, normal weight and obese adults. Int. J. Obes. Relat. Metab. Disord. J. Int. Assoc. Study Obes. 28(1): 72-79. doi:10.1038/sj.ijo.0802526.

Cooper, P.J., Taylor, M.J., Cooper, Z., and Fairbum, C.G. 1987. The development and validation of the body shape questionnaire. Int. J. Eat. Disord. 6(4): 485-494. doi:10.1002/1098108X(198707)6:4<485::AID-EAT2260060405>3.0.CO;2-O.

Cooper, Z., and Fairburn, C. 1987. The eating disorder examination: a semi-structured interview for the assessment of the specific psychopathology of eating disorders. Int. J. Eat. Disord. 6(1): 1-8. doi:10.1002/1098-108X(198701)6:1<1::AID-EAT2260060102>3.0.CO;2-9.

Covington, J.D., Johannsen, D.L., Coen, P.M., Burk, D.H., Obanda, D.N., Ebenezer, P.J., Tam, C.S., Goodpaster, B.H., Ravussin, E., and Bajpeyi, S. 2017. Intramyocellular Lipid Droplet Size Rather Than Total Lipid Content Is Related to Insulin Sensitivity After 8-Weeks of Overfeeding. Obes. Silver Spring Md 25(12): 2079-2087. doi:10.1002/oby.21980.

Essén, B., Jansson, E., Henriksson, J., Taylor, A.W., and Saltin, B. 1975. Metabolic characteristics of fibre types in human skeletal muscle. Acta Physiol. Scand. 95(2): 153-165. doi:10.1111/j.1748-1716.1975.tb10038.x.

Estour, B., Galusca, B., and Germain, N. 2014. Constitutional thinness and anorexia nervosa: a possible misdiagnosis? Front. Endocrinol. 5: 175. doi:10.3389/fendo.2014.00175.

Estour, B., Marouani, N., Sigaud, T., Lang, F., Fakra, E., Ling, Y., Diamondé, A., Minnion, J.S., Galusca, B., and Germain, N. 2017. Differentiating constitutional thinness from anorexia nervosa in DSM 5 era. Psychoneuroendocrinology 84: 94-100. doi:10.1016/j.psyneuen.2017.06.015.

Fernández-García, D., Rodríguez, M., García Alemán, J., García-Almeida, J.M., Picón, M.J., Fernández-Aranda, F., and Tinahones, F.J. 2009. Thin healthy women have a similar low bone mass to women with anorexia nervosa. Br. J. Nutr. 102(5): 709-714. doi:10.1017/S0007114509274733.

Fricke, O., and Schoenau, E. 2007. The "Functional Muscle-Bone Unit": probing the relevance of mechanical signals for bone development in children and adolescents. Growth Horm. IGF Res. Off. J. Growth Horm. Res. Soc. Int. IGF Res. Soc. 17(1): 1-9. doi:10.1016/j.ghir.2006.10.004.

Galusca, B., Prévost, G., Germain, N., Dubuc, I., Ling, Y., Anouar, Y., Estour, B., and Chartrel, N. 2015. Neuropeptide $Y$ and $\alpha-M S H$ circadian levels in two populations with low body weight: anorexia nervosa and constitutional thinness. PloS One 10(3): e0122040. doi:10.1371/journal.pone.0122040.

Galusca, B., Verney, J., Meugnier, E., Ling, Y., Edouard, P., Feasson, L., Ravelojaona, M., Vidal, H., Estour, B., and Germain, N. 2018. Reduced fibre size, capillary supply and mitochondrial activity in constitutional thinness' skeletal muscle. Acta Physiol. Oxf. Engl. 224(3): e13097. doi:10.1111/apha.13097.

Galusca, B., Zouch, M., Germain, N., Bossu, C., Frere, D., Lang, F., Lafage-Proust, M.-H., Thomas, T., Vico, L., and Estour, B. 2008. Constitutional thinness: unusual human phenotype of low bone quality. J. Clin. Endocrinol. Metab. 93(1): 110-117. doi:10.1210/jc.2007-1591.

Garner, D.M., Olmstead, M.P., and Polivy, J. 1983. Development and validation of a multidimensional eating disorder inventory for anorexia nervosa and bulimia. Int. J. Eat. Disord. 2(2): 15-34. doi:10.1002/1098-108X(198321)2:2<15::AID-EAT2260020203>3.0.CO;2-6. 
Genest, J., Adamkiewicz, L., Robillard, R., and Tremblay, G. 1955. Clinical uses of rauwolfia. II. In psoriasis and in constitutional leanness. Can. Med. Assoc. J. 72(7): 490-491.

Germain, N., Galusca, B., Caron-Dorval, D., Martin, J.-F., Pujos-Guillot, E., Boirie, Y., Khalfallah, Y., Ling, Y., Minnion, J.S., Bloom, S.R., Epelbaum, J., and Estour, B. 2014. Specific appetite, energetic and metabolomics responses to fat overfeeding in resistant-to-bodyweight-gain constitutional thinness. Nutr. Diabetes 4(7): e126. doi:10.1038/nutd.2014.17.

Germain, N., Galusca, B., Le Roux, C.W., Bossu, C., Ghatei, M.A., Lang, F., Bloom, S.R., and Estour, B. 2007. Constitutional thinness and lean anorexia nervosa display opposite concentrations of peptide YY, glucagon-like peptide 1, ghrelin, and leptin. Am. J. Clin. Nutr. 85(4): 967-971. doi:10.1093/ajen/85.4.967.

Germain, N., Viltart, O., Loyens, A., Bruchet, C., Nadin, K., Wolowczuk, I., Estour, B., and Galusca, B. 2016. Interleukin-7 plasma levels in human differentiate anorexia nervosa, constitutional thinness and healthy obesity. PloS One 11(9): e0161890. doi:10.1371/journal.pone.0161890.

Grafe, E. 1933. Metabolic diseases and their treatment - Chapter VIII: Constitutional undernutrition of doubtful origin. Lea \& Febiger.

Hardie, D.G. 2004. The AMP-activated protein kinase pathway--new players upstream and downstream. J. Cell Sci. 117(Pt 23): 5479-5487. doi:10.1242/jcs.01540.

Harris, B.A. 2005. The influence of endurance and resistance exercise on muscle capillarization in the elderly: a review. Acta Physiol. Scand. 185(2): 89-97. doi:10.1111/j.1365-201X.2005.01461.x.

Hasegawa, A., Usui, C., Kawano, H., Sakamoto, S., and Higuchi, M. 2011. Characteristics of body composition and resting energy expenditure in lean young women. J. Nutr. Sci. Vitaminol. (Tokyo) 57(1): 74-79. doi:10.3177/jnsv.57.74.

Hearris, M.A., Hammond, K.M., Fell, J.M., and Morton, J.P. 2018. Regulation of Muscle Glycogen Metabolism during Exercise: Implications for Endurance Performance and Training Adaptations. Nutrients 10(3). doi:10.3390/nu10030298.

Iqbal, R., Rafique, G., Badruddin, S., Qureshi, R., and Gray-Donald, K. 2006. Validating MOSPA questionnaire for measuring physical activity in Pakistani women. Nutr. J. 5(1): 18. doi:10.1186/1475-2891-5-18.

Kadereit, B., Kumar, P., Wang, W.-J., Miranda, D., Snapp, E.L., Severina, N., Torregroza, I., Evans, T., and Silver, D.L. 2008. Evolutionarily conserved gene family important for fat storage. Proc. Natl. Acad. Sci. U. S. A. 105(1): 94-99. doi:10.1073/pnas.0708579105.

Liang, H., and Ward, W.F. 2006. PGC-1alpha: a key regulator of energy metabolism. Adv. Physiol. Educ. 30(4): 145-151. doi:10.1152/advan.00052.2006.

Ling, Y., Carayol, J., Galusca, B., Canto, C., Montaurier, C., Matone, A., Vassallo, I., Minehira, K., Alexandre, V., Cominetti, O., Núñez Galindo, A., Corthésy, J., Dayon, L., Charpagne, A., Métairon, S., Raymond, F., Descombes, P., Casteillo, F., Peoc'h, M., Palaghiu, R., Féasson, L., Boirie, Y., Estour, B., Hager, J., Germain, N., and Gheldof, N. 2019. Persistent low body weight in humans is associated with higher mitochondrial activity in white adipose tissue. Am. J. Clin. Nutr. 110(3): 605-616. doi:10.1093/ajcn/nqz144.

Ling, Y., Galusca, B., Hager, J., Feasson, L., Valsesia, A., Epelbaum, J., Alexandre, V., Wynn, E., Dinet, C., Palaghiu, R., Peoc'h, M., Boirie, Y., Montaurier, C., Estour, B., and Germain, N. 2016. Rational and design of an overfeeding protocol in constitutional thinness: Understanding the physiology, metabolism and genetic background of resistance to weight gain. Ann. Endocrinol. 77(5): 563-569. doi:10.1016/j.ando.2016.06.001.

Ling, Y., Galusca, B., Martin, F.-P., Bartova, S., Carayol, J., Moco, S., Epelbaum, J., Grouselle, D., Boirie, Y., Montaurier, C., Cuenco, J., Minnion, J.S., Thomas, T., Mure, S., Hager, J., Estour, B., Gheldof, N., and Germain, N. 2020. Resistance to lean mass gain in constitutional thinness in free-living conditions is not overpassed by overfeeding. J. Cachexia Sarcopenia Muscle n/a(n/a). doi:10.1002/jcsm.12572.

Margaritelis, N.V., Theodorou, A.A., Kyparos, A., Nikolaidis, M.G., and Paschalis, V. 2019. Effect of body composition on redox homeostasis at rest and in response to exercise: the case of underfat women. J. Sports Sci. 37(6): 1-8. doi:10.1080/02640414.2019.1578450. 
Marra, M., Caldara, A., Montagnese, C., De Filippo, E., Pasanisi, F., Contaldo, F., and Scalfi, L. 2009. Bioelectrical impedance phase angle in constitutionally lean females, ballet dancers and patients with anorexia nervosa. Eur. J. Clin. Nutr. 63(7): 905-908. doi:10.1038/ejen.2008.54.

Marra, M., Pasanisi, F., Montagnese, C., De Filippo, E., De Caprio, C., de Magistris, L., and Contaldo, F. 2007. BMR variability in women of different weight. Clin. Nutr. Edinb. Scotl. 26(5): 567572. doi:10.1016/j.clnu.2007.03.006.

Marra, M., Sammarco, R., De Filippo, E., De Caprio, C., Speranza, E., Contaldo, F., and Pasanisi, F. 2019. Resting energy expenditure, body composition and phase angle in anorectic, ballet dancers and constitutionally lean males. Nutrients 11(3): 502. doi:10.3390/nu11030502.

Miranda, D.A., Koves, T.R., Gross, D.A., Chadt, A., Al-Hasani, H., Cline, G.W., Schwartz, G.J., Muoio, D.M., and Silver, D.L. 2011. Re-patterning of skeletal muscle energy metabolism by fat storage-inducing transmembrane protein 2. J. Biol. Chem. 286(49): 42188-42199. doi:10.1074/jbc.M111.297127.

Morales, P.E., Bucarey, J.L., and Espinosa, A. 2017. Muscle Lipid Metabolism: Role of Lipid Droplets and Perilipins. J. Diabetes Res. 2017(2 part 1): 1-10. doi:10.1155/2017/1789395.

Mounier, R., Chrétien, F., and Chazaud, B. 2011. Blood vessels and the satellite cell niche. Curr. Top. Dev. Biol. 96: 121-138. doi:10.1016/B978-0-12-385940-2.00005-X.

Pasanisi, F., Pace, L., Fonti, R., Marra, M., Sgambati, D., De Caprio, C., De Filippo, E., Vaccaro, A., Salvatore, M., and Contaldo, F. 2013. Evidence of brown fat activity in constitutional leanness. J. Clin. Endocrinol. Metab. 98(3): 1214-1218. doi:10.1210/jc.2012-2981.

Passmore, R., Meiklejohn, A.P., Dewar, A.D., and Thow, R.K. 1955. Energy utilization in overfed thin young men. Br. J. Nutr. 9(1): 20-27.

Riveros-McKay, F., Mistry, V., Bounds, R., Hendricks, A., Keogh, J.M., Thomas, H., Henning, E., Corbin, L.J., Understanding Society Scientific Group, O’Rahilly, S., Zeggini, E., Wheeler, E., Barroso, I., and Farooqi, I.S. 2019. Genetic architecture of human thinness compared to severe obesity. PLoS Genet. 15(1): e1007603. doi:10.1371/journal.pgen.1007603.

Saha, A.K., and Ruderman, N.B. 2003. Malonyl-CoA and AMP-activated protein kinase: an expanding partnership. Mol. Cell. Biochem. 253(1-2): 65-70. doi:10.1023/A:1026053302036.

Scalfi, L., Coltorti, A., Borrelli, R., and Contaldo, F. 1992. Postprandial thermogenesis in leanness and anorexia nervosa. Ann. Nutr. Metab. 36(1): 48-54. doi:10.1159/000177698.

Staron, R.S., Hagerman, F.C., Hikida, R.S., Murray, T.F., Hostler, D.P., Crill, M.T., Ragg, K.E., and Toma, K. 2000. Fiber Type Composition of the Vastus Lateralis Muscle of Young Men and Women. J. Histochem. Cytochem. 48(5): 623-629. doi:10.1177/002215540004800506.

van Strien, T., Frijters, J.E.R., Bergers, G.P.A., and Defares, P.B. 1986. The Dutch Eating Behavior Questionnaire (DEBQ) for assessment of restrained, emotional, and external eating behavior. Int. J. Eat. Disord. 5(2): 295-315. doi:10.1002/1098-108X(198602)5:2<295::AIDEAT2260050209>3.0.CO;2-T.

Tagami, T., Satoh, N., Usui, T., Yamada, K., Shimatsu, A., and Kuzuya, H. 2004. Adiponectin in anorexia nervosa and bulimia nervosa. J. Clin. Endocrinol. Metab. 89(4): 1833-1837. doi:10.1210/jc.2003-031260.

Toledo, F.G.S., Johannsen, D.L., Covington, J.D., Bajpeyi, S., Goodpaster, B., Conley, K.E., and Ravussin, E. 2018. Impact of prolonged overfeeding on skeletal muscle mitochondria in healthy individuals. Diabetologia 61(2): 466-475. doi:10.1007/s00125-017-4496-8.

Winder, W.W. 2001. Energy-sensing and signaling by AMP-activated protein kinase in skeletal muscle. J. Appl. Physiol. 91(3): 1017-1028. doi:10.1152/jappl.2001.91.3.1017.

Wissmer, B. 1953. [Treatment of constitutional thinness]. Arch. Mal. Appar. Dig. Mal. Nutr. 42(2): 149-157 
Supplementary Table S1: Composition of the Renutryl ${ }^{\circledR}$ Booster overfeeding

\begin{tabular}{lll}
\hline $\begin{array}{l}\left.\text { Renutryl }{ }^{\circledR} \text { Booster } \mathbf{( 3 0 0 ~} \mathbf{~ m l}\right) \\
\text { Energy }\end{array}$ & $\mathrm{kcal}$ & 600 \\
\hline $\begin{array}{l}\text { Fat } \\
31.5 \% \text { kcal }\end{array}$ & $\mathrm{g}$ & 21 \\
\hline $\begin{array}{l}\text { Carbohydrate } \\
48.5 \% \text { kcal }\end{array}$ & $\mathrm{g}$ & 72 \\
$\quad$ of which sugars & $\mathrm{g}$ & 21 \\
$\quad$ of which lactose & $\mathrm{g}$ & $<1.5$ \\
\hline Protein & $\mathrm{g}$ & 30 \\
20\% kcal & & \\
\hline Minerals & & \\
$\quad$ Sodium & $\mathrm{mg}$ & 285 \\
$\quad$ Potassium & $\mathrm{mg}$ & 720 \\
Calcium & $\mathrm{mg}$ & 687 \\
$\quad$ Phosphate & $\mathrm{mg}$ & 459 \\
\hline
\end{tabular}

Renutryl ${ }^{\circledR}$ Booster is a hyper-caloric $(2 \mathrm{kcal} / \mathrm{mL})$ oral nutritional supplement providing macronutrients and micronutrients. Four flavors (vanilla, coffee, caramel, and strawberry) were proposed to the participants 